\title{
Polymer/polymer blends in organic photovoltaic and photodiode devices
}

Yuxin Xia 


\title{
Polymer/polymer blends in organic photovoltaic and photodiode devices
}

\author{
Yuxin Xia
}

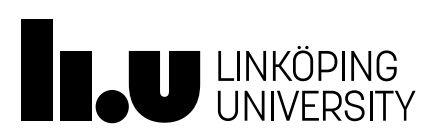

Biomolecular and Organic Electronics Department of Physics, Chemistry and Biology(IFM) Linköping University, SE-581 83 Linköping, Sweden 
Copyright (C) Yuxin Xia

Polymer/polymer blends in organic photovoltaic and photodiode devices ISSN: 0345-7524

ISBN: 978-91-7685-146-3

Printed by LiU-Tryck. Linköping, Sweden,2018 


\section{Abstract}

Organic photovoltaics devices (OPV) have attracted attentions of scientist for their potential as inexpensive, lightweight, flexible and suitable for roll-to-roll production. In recent years, considerable attention has been focused on new acceptor materials, either polymeric or small molecules, to replace the once dominating fullerene derivatives. The emergence of numerous new non-fullerene materials has driven power conversion efficiency (PCE) up to $17 \%$, attracting more and more interests of commercialization.

Polymer acceptors with more morphology stability, more absorption and more desired energy levels has been intensively studied and show great potential for large area and low-cost production in the future. OPV at this moment is not yet competitive with inorganic solar cells in PCE but is more attractive in flexibility, low weight and semitransparency. In this thesis, some basic knowledges of OPV is introduced in the first few chapters, while the next chapters are focusing on polymer-polymer blends and investigating novel structures and techniques for large scale production of solar cells and photodetectors aiming at maximizing these advantages to compete with inorganic counterpart.

Thermal annealing effects on polymer-polymer solar cells based is studied. Annealed devices show doubled power conversion efficiency compared to non-annealed devices. Based on the morphology-mobility examination, we conclude that the better charge transport is achieved by higher order and better interconnected networks of the bulk heterojunction in the annealed active layers. The annealing improves charge transport and extends the conjugation length of the polymers, which do help charge generation and meanwhile reduce recombination. The blend of an amorphous polymer and a semi-crystalline polymer can thus be modified by thermal annealing to double the power conversion efficiency.

A novel concept of all-polymer organic photovoltaics device is demonstrated in this thesis where all the layers are made out of polymers. We use PEDOT:PSS as semitransparent anode and polyethyleneimine modified PEDOT:PSS as semitransparent cathode, both of which are slot-die printed on polyethylene terephthalate(PET). Active layers are deposited on cathode and anode surfaces by spin coating separately. These layers are then joined through a roll-toroll compatible lamination process. This forms a semitransparent and flexible solar cell. By 
laminating a thin layer acceptor polymer to a thick polymer-polymer blend, we can further improve the performance by reducing traps comparing to laminating blend to blend.

Flexible and semitransparent all-polymer photodiodes with different geometries can be fabricated through lamination. By choosing high band gap polymers and appropriate combination of two or more polymers, organic photodiode with low noise and high specific detectivity can be obtained. Comparison between bilayer and bulk heterojunction devices gives better understanding of the origin of noise and provides ways to improve the performance of photodiodes as detector.

Noise level is a critical parameter for photodetectors. The difficulties of measuring the noise of photodetectors make some researchers prefer the estimated shot noise as the dominating one and ignore the thermal noise and $1 / f$ noise. The latter two terms can sometimes be several orders of magnitude higher than the former, noting the importance of experimentally measuring noise.

The use of semi-transparent photovoltaic devices causes an inevitable loss of photocurrent, as light transmitted has not been absorbed. This trivial effect also leads to a loss of photovoltage, an effect partially due to the lower photocurrent but also due to the geometry of the semitransparent photovoltaic device. We here demonstrate and evaluate this photovoltage loss in semi-transparent organic photovoltaic devices, compared with non-transparent solar cells of the same material. Semi-transparent solar cells in addition introduce photovoltage loss when formed by lamination. We document and analyze these effects for a number of polymer blends in the form of bulk heterojunctions. 


\section{Populärvetenskaplig Sammanfattning}

Organiska solceller byggs med blandningar av två organiska material, och kan vara billiga, lätta, böjliga och lämpliga för tillverkning med rulle-till-rulle metoder. De senaste åren har nya acceptor material, i polymer eller molekylformat, börjat ersätta tidigare dominerande fullerenderivat. Detta har möjliggjort mer effektiva solceller, upp till 17\%, vilket ökar intresset för kommersialisering. Polymera acceptorer med bättre morfologisk stabilitet, högre optisk absorption och lämpliga energinivåer har stor potential för billig produktion av organiska/polymera solmoduler och användning på stora ytor. Organiska solceller är ännu inte konkurrenskraftiga genom sin effektivitet, men har attraktiva egenskaper i form av låg vikt, böjlighet och kan tillverkas i halvgenomskinliga komponenter. I denna avhandling beskrivs organiska solcellers fysik och speciellt polymer/polymer blandningar i organiska solceller. Nya konstruktionsmetoder och byggtekniker för halvgenomskinliga solceller redovisas, i syfte att vidareutveckla dessa komponenter och material för användning i organiska solceller och fotodetektorer. Värmebehandling av polymer/polymer blandningar kan fördubbla effektiviteten i organiska solceller, och i avhandlingen redovisas studier av morfologi och elektrisk transport i dessa material. Nanostrukturen i en landning av en amorf och en delkristallin polymer förändras vid värmebehandlingen. Förbättringen orsakas av såväl förstärkt bildning av fria laddningar, minskad rekombination och förbättrade transportvillkor för fotogenerade laddningar. Den förändrade morfologin ger bättre förbindning mellan domäner för elektron respektive håltransport.

I en ny typ av organiska solceller har alla funktioner - som substrat, elektrod, selektiva kontaktlager och aktivt fotovoltaiskt material-utformats i polymera material. Dessa endastpolymer baserade organiska solceller och fotodioder använder halvtransparenta skikt av den dopade polymeren PEDOT(PSS) som elektroder, och modifierar en elektrod med poly(etylenimin) för att skapa en selektiv katod. Elektroderna bestrykes på ett transparent substrat av polyetentereftalat (PET). Det aktiva lagret deponeras på dessa separata elektroder, och lamineras samman under förhöjd tryck och temperatur. På så sätt erhålles en 
halvtransparent och flexibel organisk solcell. Genom att laminera ett tunt skikt av acceptor till ett aktivt material i en blandning kan koncentrationen av defekttillstånd minskas. Halvtransparenta solceller leder också till en liten men oundviklig förlust av fotospänning.

Fotodioder kan konstrueras på samma sätt, och möjliggör flexibla fotodetektorer med lågt brus och hög detektivitet. En jämförelse mellan laminerade fotodetektorer med två skikt av donor och acceptor (bilager) respektive blandning av donor och acceptor visar på möjigheten att minska bruset och att därigenom konstruera bättre fotodioder. Brusmätningar visar att de enklaste modellerna för brus inte förutsäger realistiska brusnivåer. 


\section{List of publications}

Papers included in this thesis

1. Inverted all-polymer solar cells based on a quinoxaline-thiophene/naphthalene-diimide polymer blend improved by annealing. Journal of Materials Chemistry A 4(10): 3835-3843.

Xia, Yuxin, Chiara Musumeci, Jonas Bergqvist, Wei Ma, Feng Gao, Zheng Tang, Sai Bai, Yizheng Jin, Chenhui Zhu and Renee Kroon, Olle Inganäs, Ergang Wang (2016).

2. Semitransparent All-Polymer Solar Cells Through Lamination. Journal of Materials Chemistry $\underline{A}, 2018,6,21186-21192$

Yuxin Xia, Xiaofeng Xu, Luis Ever Aguirre, Olle Inganäs*

3. Lamination of organic layers for all-polymer organic photodetector Manuscript

Yuxin Xia, Xiaofeng Xu, Olle Inganäs*

4. Large-Area, Semitransparent, and Flexible All-Polymer Photodetectors. Adv.Funct.Mater. $\underline{2018,28,1805570}$

Xiaofeng Xu, Xiaobo Zhou, Ke Zhou, Yuxin Xia, Wei Ma, * and Olle Inganäs*

5.Photovoltage Loss in Semi-transparent Organic Photovoltaic Devices

Manuscript

Yuxin Xia, Olle Inganäs*

\section{Author's contributions to the publications.}

Paper1: Wrote most part of the manuscript and did experiments except C-AFM, GWAXS, Ellipsometry measurements.

Paper 2-3:Wrote the manuscript and did most of the experiments.

Paper4: Noise measurements.

Paper5: Wrote part of the manuscript and did all the experiments and data analysis. 


\section{Papers not included into this thesis}

1. Bakulin, Artem A, Yuxin Xia, Huib J Bakker, Olle Inganäs and Feng Gao (2016). "Morphology, Temperature, and Field Dependence of Charge Separation in High-Efficiency Solar Cells Based on Alternating Polyquinoxaline Copolymer." The Journal of Physical Chemistry C 120(8): 4219-4226. Contribution: Solar cells preparation and PL measurements

2. Gao, Feng, Scott Himmelberger, Mattias Andersson, David Hanifi, Yuxin Xia, Shaoqing Zhang, Jianpu Wang, Jianhui Hou, Alberto Salleo and Olle Inganäs (2015). "The Effect of Processing Additives on Energetic Disorder in Highly Efficient Organic Photovoltaics: A Case Study on PBDTTT-C-T: PC71BM." Advanced Materials 27(26): 3868-3873.

Contribution: Samples preparation and PL\EL measurements

3. George, Zandra, Yuxin Xia, Anirudh Sharma, Camilla Lindqvist, Gunther Andersson, Olle Inganäs, Ellen Moons, Christian Müller and Mats R Andersson (2016). "Two-in-one: cathode modification and improved solar cell blend stability through addition of modified fullerenes." Journal of Materials Chemistry A 4(7): 2663-2669.

Contribution: Device preparation, optimization and Rs Rp calculation.

4. Li, Yongxi, Xiaodong Liu, Fu-Peng Wu, Yi Zhou, Zuo-Quan Jiang, Bo Song, Yuxin Xia, Zhi-Guo Zhang, Feng Gao and Olle Inganäs (2016). "Non-fullerene acceptor with low energy loss and high external quantum efficiency: towards high performance polymer solar cells." Journal of Materials Chemistry A 4(16): 5890-5897.

Contribution: FTPS and EL measurements, discussion and interpretation of experiments results.

5. Lin, Yuze, Fuwen Zhao, Yang Wu, Kai Chen, Yuxin Xia, Guangwu Li, Shyamal KK Prasad, Jingshuai Zhu, Lijun Huo and Haijun Bin (2017). "Mapping Polymer Donors toward High-Efficiency Fullerene Free Organic Solar Cells." Advanced Materials 29(3).

Contribution: FTPS and EL measurements, discussion and interpretation of experiments results.

6. Melianas, Armantas, Vytenis Pranculis, Yuxin Xia, Nikolaos Felekidis, Olle Inganäs, Vidmantas Gulbinas and Martijn Kemerink (2017). "Photogenerated Carrier Mobility Significantly Exceeds Injected Carrier Mobility in Organic Solar Cells." Advanced Energy Materials 7(9).

Contribution: Samples preparation

7. Peng, Zuosheng, Yuxin Xia, Feng Gao, Kang Xiong, Zhanhao Hu, David lan James, Junwu Chen, Ergang Wang and Lintao Hou (2015). "A dual ternary system for highly efficient ITO-free inverted polymer solar cells." Journal of Materials Chemistry A 3(36): 18365-18371. 
Contribution: FTPS and EL measurements, discussion and interpretation of experiments results.

8. Peng, Zuosheng, Yangdong Zhang, Yuxin Xia, Kang Xiong, Chaosheng Cai, Lianpeng Xia, Zhanhao Hu, Kai Zhang, Fei Huang and Lintao Hou (2015). "One-step coating inverted polymer solar cells using a conjugated polymer as an electron extraction additive." Journal of Materials Chemistry A 3(41): 2050020507.

Contribution: FTPS and EL measurements, discussion and interpretation of experiments results.

9. Puttisong, Y, F Gao, Y Xia, IA Buyanova, O Inganäs and WM Chen (2017). Optically detected magnetic resonance studies of the interfacial charge transfer exciton in polymer-fullerene solar cells. APS March Meeting Abstracts.

Contribution: Samples preparation

10. Tao, Qiang, Yuxin Xia, Xiaofeng Xu, Svante Hedström, Olof Bäcke, David I James, Petter Persson, Eva Olsson, Olle Inganäs and Lintao Hou (2015). "D-A1-D-A2 copolymers with extended donor segments for efficient polymer solar cells." Macromolecules 48(4): 1009-1016.

Contribution: First co-author, samples fabrication and optimization, characterization including EQE, AFM

11. Tauber, Daniela, Yuxi Tian, Yuxin Xia, Olle Inganäs and Ivan G Scheblykin (2017). "Nanoscale Chain Alignment and Morphology in All-Polymer Blends Visualized Using 2D Polarization Fluorescence Imaging: Correlation to Power Conversion Efficiencies in Solar Cells." The Journal of Physical Chemistry C 121(40): 21848-21856.

Contribution: Samples preparation.

12. Wang, Chuanfei, Xiaofeng Xu, Wei Zhang, Jonas Bergqvist, Yuxin Xia, Xiangyi Meng, Kim Bini, Wei Ma, Arkady Yartsev and Koen Vandewal (2016). "Low band gap polymer solar cells with minimal voltage losses." Advanced Energy Materials 6(18).

Contribution: Some discussion

13. Elfwing, Anders, Wanzhu Cai, Liangqi Ouyang, Xianjie Liu, Yuxin Xia, Zheng Tang and Olle Inganäs (2018). "DNA Based Hybrid Material for Interface Engineering in Polymer Solar Cells." ACS Applied Materials \& Interfaces 10(11): 9579-9586.

Contribution: Some discussion and manuscript reviewing.

14.Jasiūnas, Rokas, Armantas Melianas, Yuxin Xia, Nikolaos Felekidis, Vidmantas Gulbinas and Martijn Kemerink (2018). "Dead Ends Limit Charge Carrier Extraction from All-Polymer Bulk Heterojunction Solar Cells." Advanced Electronic Materials 4(8): 1800144.

Contribution: Samples preparation.

15. Karuthedath, Safakath, Armantas Melianas, Zhipeng Kan, Vytenis Pranculis, Markus Wohlfahrt, Jafar I 
Khan, Julien Gorenflot, Yuxin Xia, Olle Inganäs and Vidmantas Gulbinas (2018). "Thermal annealing reduces geminate recombination in TQ1: N2200 all-polymer solar cells." Journal of Materials Chemistry A 6(17): 7428-7438.

Contribution: Samples preparation.

16. Puttisong, Yuttapoom, Yuxin Xia, Xiaoqing Chen, Feng Gao, Irina A Buyanova, Olle Inganäs and Weimin M Chen (2018). "Charge Generation via Relaxed Charge Transfer States in Organic Photovoltaics by an Energy-Disorder-Driven Entropy Gain." The Journal of Physical Chemistry C. 122, 24, 12640-12646 Contribution: Samples preparation.

17. Xie, S. K., Y. X. Xia, Z. Zheng, X. N. Zhang, J. Y. Yuan, H. Q. Zhou and Y. Zhang Effects of Nonradiative Losses at Charge Transfer States and Energetic Disorder on the Open-Circuit Voltage in Nonfullerene Organic Solar Cells. Advanced Functional Materials 28(5).

Contribution: FTPS and EL measurements, Voc loss calculation and analysis. 


\section{Contents}

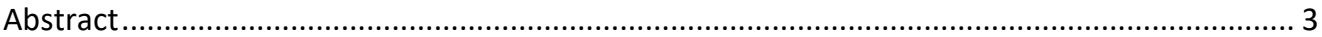

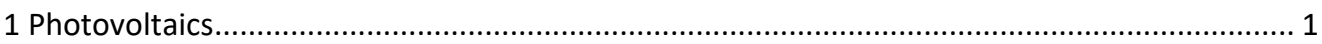

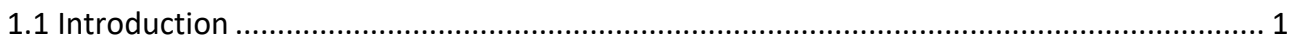

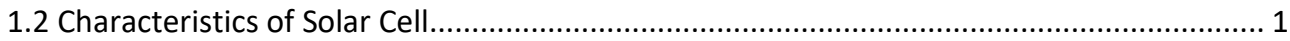

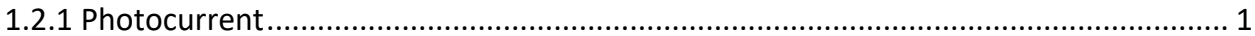

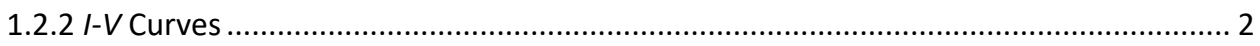

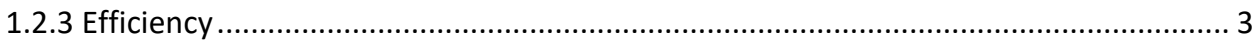

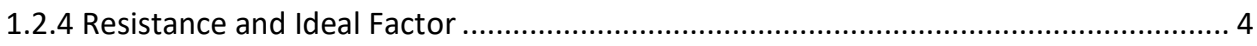

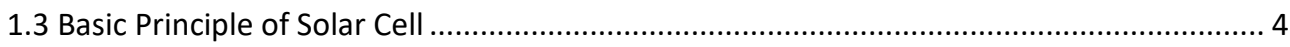

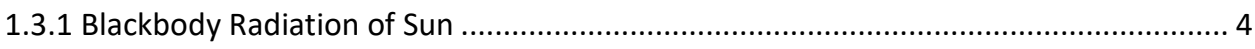

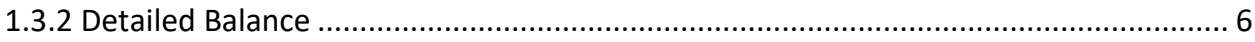

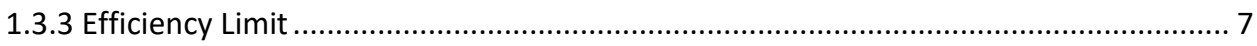

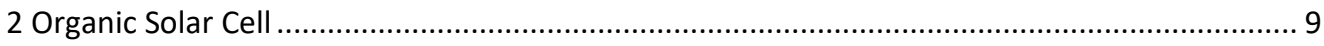

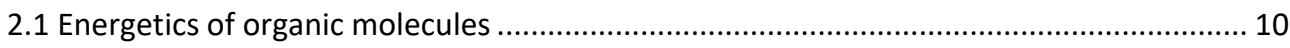

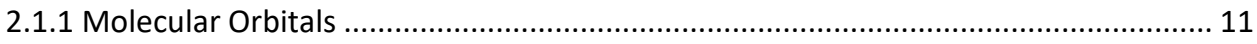

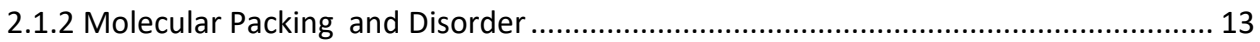

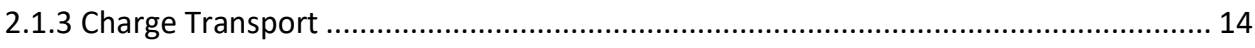

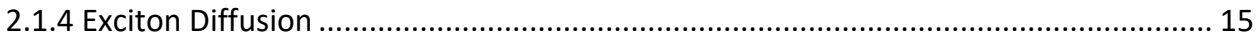

2.2 Basics of Bulk Heterojunction Solar Cell .................................................................... 16

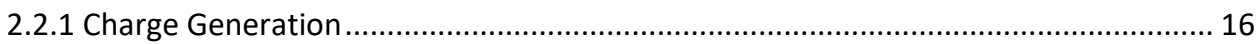

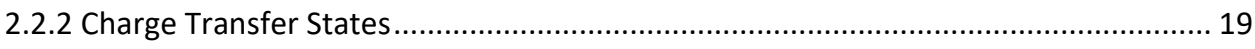

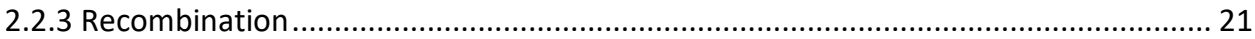




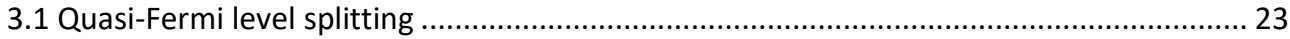

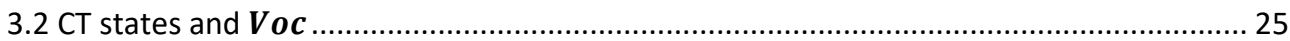

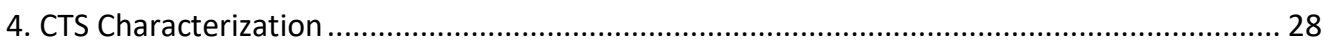

4.1 Fourier-Transform Photocurrent Spectroscopy ........................................................ 28

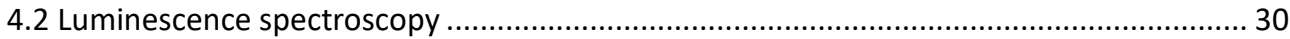

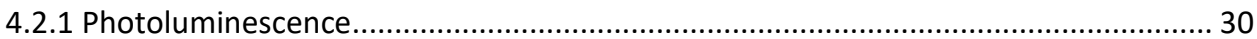

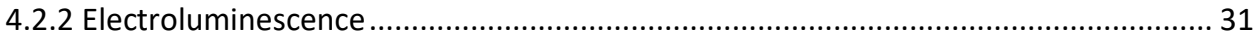

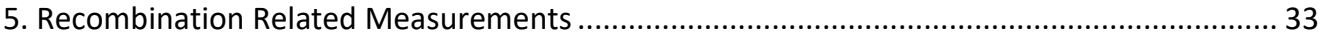

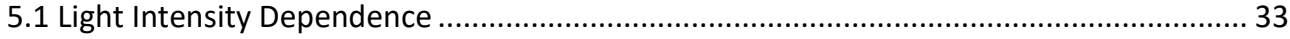

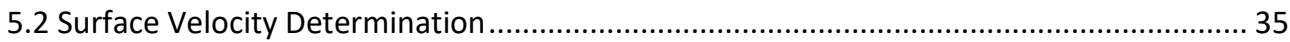

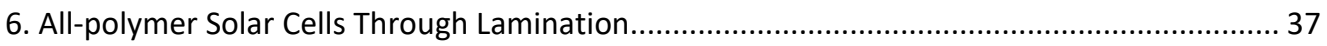

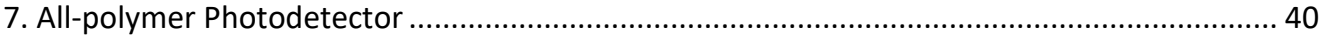

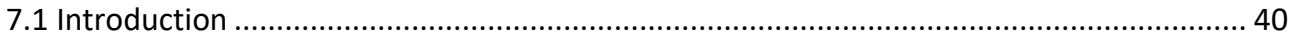

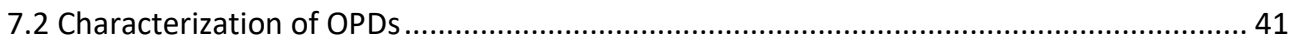

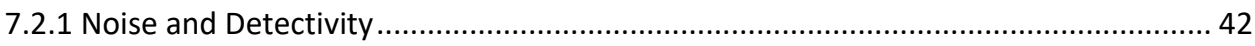

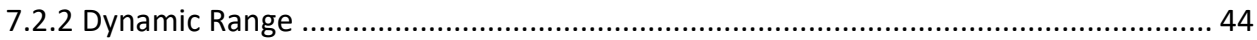

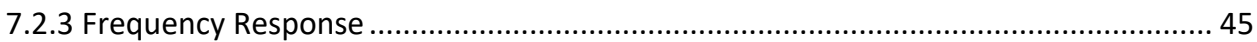

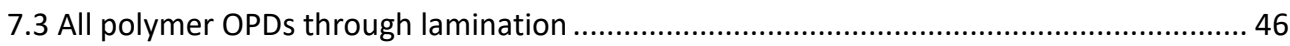

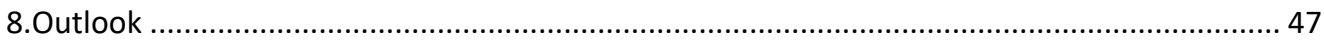

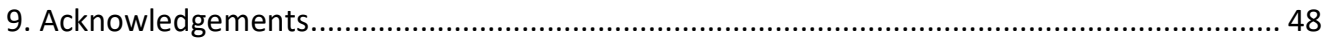

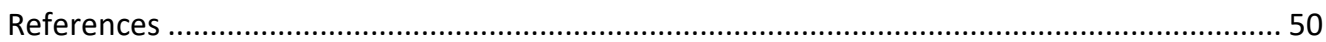

Appendix I: Chemical Structure of Involved Materials ......................................................... 58 
Appendix II: Abbreviations and Symbols 


\section{Photovoltaics}

\subsection{Introduction}

Photovoltaic conversion is a process which generate electrical energy from light energy. Light contains energy in the form of photons. These photons could interact with light absorbers and excite electrons from lower energy level and bound states into higher energy levels where they can move freely. For the simplest example, if the photon energy is higher than the energy difference between two states, then transition could occur. More precise determination of possibility of this transition is according to the transition moment, the overlapping of wavefunction of these two states.

Sometimes, if the photon energy is so high that excited electrons get enough energy to escape from solid surface then we call it photoelectric effect. By elaborated explanation of this phenomena, Einstein won 1905 Nobel Prize. But for most cases, the excited electrons would collide with its surroundings and soon lose its energy to lattice temperature. With the excess energy, a potential could be generated. If we can build a structure which can pull these electrons out before they lose all the excess energy and use this potential to create work on loads, then we call this structure a photovoltaics device or a solar cell.

\subsection{Characteristics of Solar Cell}

\subsubsection{Photocurrent}

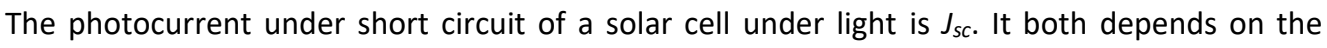
incident light and its external quantum efficiency (EQE). The EQE is the probability to generate one electron per incident photon.

$$
J_{\mathrm{sc}}=q \int f_{S}(E) E Q E(E) d E
$$

$f_{\mathrm{s}}(\mathrm{E})$ is spectral photon flux, the number of photons with energy in the interval from $E$ to $E+\mathrm{d} E$ per unit time and per unit area. The EQE depends on the absorption coefficient of materials, charge generation efficiency and charge collection efficiency. The ratio between the EQE and absorption of a solar cell is the internal quantum efficiency(IQE), i.e. the probability of 
generating one electron per absorbed photon. EQE can be function of energy or wavelength, with relationship like this,

$$
E=\frac{h c}{\lambda}=\frac{1240}{\lambda}, \text { where } \mathrm{E} \text { in } \mathrm{eV} \text { and } \lambda \text { in } \mathrm{nm} .
$$

For solar spectral irradiance the most widely used reference is the AM 1.5 G Spectra, in photovoltaic industry and academic field. The spectral photon flux is easily obtained from the spectral irradiance spectra. Therefore, we could calculate the $J_{\mathrm{sc}}$ of a solar cell by integrating the EQE spectra.
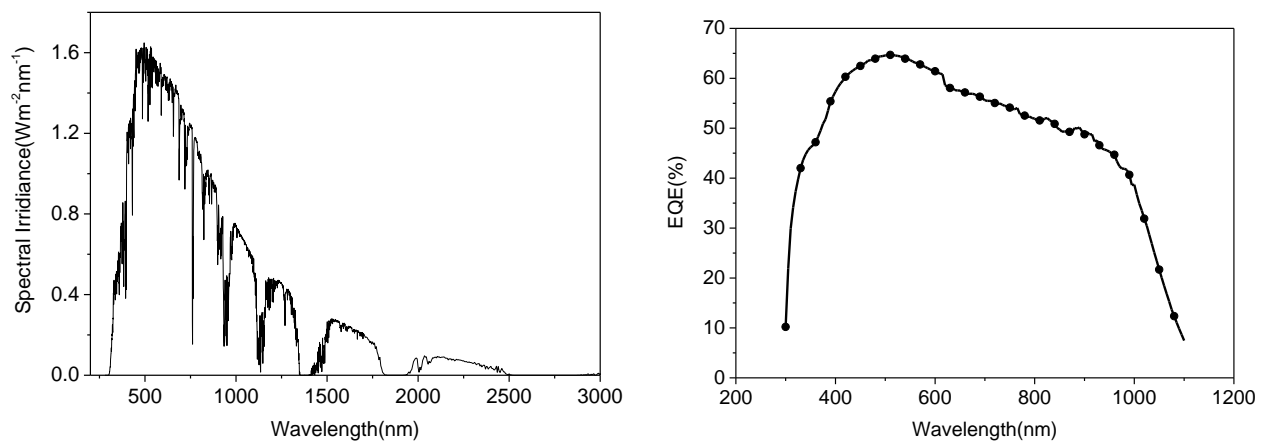

Figure 1.1 AM 1.5G spectra from ASTM G-173-03 and typical EQE spectra of silicon solar cell.

\subsubsection{I-V Curves}

Without light, solar cells works as a diode, so the current in dark $J_{\text {dark }}$ obeys the basic equation, with rectifying features, much higher current under forward bias than reverse bias.

$$
J_{\text {dark }}=J_{0}\left(e^{\frac{q V}{k_{B} T}}-1\right)
$$

$J_{0}$ is the saturation current, $k_{\mathrm{B}}$ is Boltzmann constant and $\mathrm{T}$ temperature. Under light, the potential generated by excited electrons will result in a current through an outside circuit, whose direction is opposite to the photocurrent inside the solar cell. This current would decrease with increasing load and is lower than the $J_{\text {sc }}$. With superposition of dark and light current, we get the total current as: 


$$
J=J_{S c}-J_{0}\left(e^{\frac{q V}{k_{B} T}}-1\right)
$$

When there is infinite large load or open circuit condition, then current is zero and the potential maintains the maximum, the voltage it gives to outside circuit then is what we call open circuit voltage $V_{\text {oc }}$. Set $J=0$ in equation 1.3 , we get:

$$
V_{o c}=\frac{k_{B} T}{q} \ln \left(\frac{J_{S C}}{J_{0}}+1\right)
$$

The $V_{\text {oc }}$ increases logarithmically with light intensity and linearly with temperature. Electrically, the solar cell is an analogue to a current source in parallel with a diode. When illuminated, the cell produces a current and the current is affected with internal shunt and series resistance and outside load.
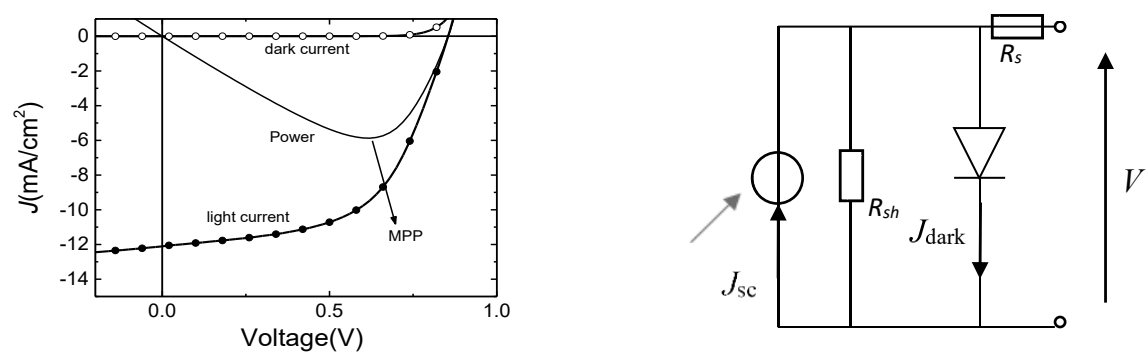

Figure $1.2 \mathrm{I}-\mathrm{V}$ curves and equivalent circuit of solar cell.

\subsubsection{Efficiency}

Solar cells operate in the fourth quadrant in Figure 1.2, where the output voltage and current have same direction and the power $\mathrm{P}=J V$. Under certain load, $\mathrm{P}$ reaches the highest $\mathrm{Pm}$, and the fill factor (FF) is defined as

$$
F F=\frac{J_{m} V_{m}}{J_{s c} V_{o c}}
$$

FF describes how square the IV curves are and under how large range it maintains the current with changing of load. The power conversion efficiency(PCE) then is defined as the power density delivered as a ratio to the input light power density, $\mathrm{P}_{\mathrm{s}}$ 


$$
P C E=\frac{J_{m} V_{m}}{P_{S}}=\frac{J_{s c} V_{o c}}{P_{S}} F F
$$

These four parameters are the key characteristics of solar cell. They must be defined under particular temperature and illumination condition. The standard condition is at $25^{\circ} \mathrm{C}$ under AM $1.5 \mathrm{G}$ with $\mathrm{P}_{\mathrm{s}}$ as $1000 \mathrm{~W} / \mathrm{m}^{2}$.

\subsubsection{Resistance and Ideal Factor}

In a real solar cell, there are contact resistance and bulk resistance as series resistance as well as leakage pathways identified as shunt resistance. Series resistance $R_{S}$ is an issue at high currents, like under high light intensity. The shunt resistance $\mathrm{R}_{s h}$ is related with recombination loss, either at contact or in the bulk of device. Both series and shunt resistance reduce the FF. When considering the resistance, the equation 1.4 is modified as

$$
J=J_{S C}-J_{0}\left(e^{\frac{q\left(V+J R_{S}\right)}{n k_{B} T}}-1\right)-\frac{(\mathrm{V}+J R)}{\mathrm{R}_{S h}}
$$

There is another parameter accounting for the recombination, the ideality factor $\mathrm{n}$, which describes the voltage dependence of current.

\subsection{Basic Principle of Solar Cell}

In the previous part, characteristics of solar cell are introduced and defined. In this subchapter, the basic principle of solar cell is addressed in the thermodynamic aspects. Solar cell along with the sun make up a system, with sun as heat source and solar cell as heat engine. There is always efficiency limitation for any thermodynamic system, according to the second law of thermodynamics. Detailed balanced theory is introduced to calculate the performance of solar cell.

\subsubsection{Blackbody Radiation of Sun}

The sun is a blackbody, so the emitted light obeys the blackbody radiation law. The distribution and intensity of the spectrum is determined by the temperature, ca. $5800 \mathrm{~K}$ at the surface of sun. Close to surface of the sun, the number of photons with energy between $E$ to $E+d E$ 
emitted from unit area and unit solid angle per unit time, i.e. the spectral photon flux is given as ${ }^{[1]}$

$$
B_{S}(E, S, \theta, \varphi) d E d S d \Omega=\frac{2}{h^{3} c^{2}}\left(\frac{E^{2}}{e^{\frac{E}{k^{T}}-1}}\right) d E d S d \Omega
$$

where the $d S$ is unit area and $d \Omega$ is the solid angle, $h$ is Planck constant and $c$ is light speed. The normal to surface flux can be obtain by integrating over solid angle,

$$
\begin{aligned}
B_{S}(E, S) d E d S= & \int_{\Omega} \frac{2}{h^{3} c^{2}}\left(\frac{E^{2}}{e^{\frac{E}{k_{B} T}}-1}\right) \cos \theta d E d S d \Omega \\
& =\frac{2 F_{S}}{h^{3} c^{2}}\left(\frac{E^{2}}{e^{\frac{E}{k_{B} T}}}\right) d E d S
\end{aligned}
$$

where $F_{\mathrm{s}}$ is a geometrical factor regarding the corresponding angular range. At the surface of emitter, it is hemisphere and $F_{\mathrm{s}}=\pi$, and away from the surface, it decreases to

$$
F_{s}=\pi \sin ^{2} \theta_{\text {sun }}
$$

where $\theta_{\text {sun }}$ is the half angle subtended by the sun to the point where flux is measured at earth, which is about $0.26^{\circ}$.

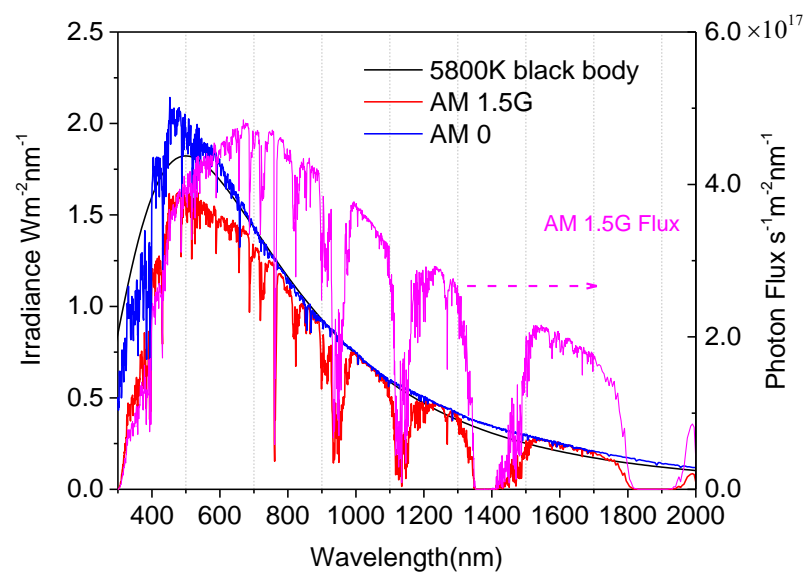


Figure 1.3 Solar spectrum (AM 1.5G) and spectral photon flux density. The spectrum outside atmosphere(AM0) follows approximately blackbody radiation at $5800 \mathrm{~K}$ with a reduction factor of $2.06^{*} 10^{-5}$, considering the angular range as $0.26^{\circ}$.

When light pass through atmosphere of earth, a fraction would be absorbed and scattered, so that the spectrum gets changed both in shape and intensity when it comes to the earth surface. Short wavelength light is mostly scattered by atmosphere molecules (blue light) and absorbed by ozone (UV light). Water and $\mathrm{CO}_{2}$ absorb light mainly in the infrared region, giving valleys around 900,1100 and $1400 \mathrm{~nm}$. The reduction by the atmosphere is quantified by 'Air Mass', representing the optical length relative to the vertically overhead optical length. The mostly used standard spectrum is AM $1.5 \mathrm{G}$ which has power density of $1000 \mathrm{~W} / \mathrm{m}^{2}$. Part of the scattered light and light reflected by earth surface make up the diffuse light, which comes from all directions. To make use of them, bifacial structure or transparent solar cells are good candidates.

\subsubsection{Detailed Balance}

Solar cells not only absorb light from sun but also will absorb light from surroundings, because if the surrounding has a temperature, it would emit light according to blackbody radiation, and so does solar cells. Solar cell both absorb and emit photons and the rates should be matched so that generation rate of electrons keeps constant in steady state.

Under dark condition, the cell stays in thermal equilibrium with surroundings, the absorbed photons should balance the emitted photons. Equivalent absorption current equals the equivalent emission current and therefore in theory the current is 0 under short-circuit condition.

$$
j_{a b s}(E)=j_{\text {em }}(E)=q(1-R(E)) a(E) B_{a}(E)
$$

$R(E)$ is the possibility of photon reflected, $a(E)$ is the possibility of absorption of photon with energy $E$ or emission of a photon with energy $E, B_{a}(E)=\frac{2 F_{a}}{h^{3} c^{2}} \frac{E^{2}}{e^{\frac{E-\Delta \mu}{k^{T} T_{a}}}-1}$ is the incident flux of thermal photons normal to the surface with geometrical factor $F_{a}$ as $\pi$ for incidence over a 
hemisphere. It is notable that for semitransparent devices, the absorption current should be doubled since the thermal photon receiving area is doubled $F_{a}=2 \pi$.

Under illumination by solar irradiation, then absorption includes two parts, solar photons and thermal photons. The equivalent absorption current density is

$$
j_{a b s}(E)=q(1-R(E)) a(E)\left(B_{s}(E)+F * B_{a}(E)\right)
$$

$\mathrm{F}=1-\frac{F_{S}}{F_{a}}$ is introduced for fraction of total incident flux, as replacing of thermal radiation with solar radiation within certain angular range. Since the angular range of solar radiation is much smaller than ambient radiation $\left(0.26^{\circ} \mathrm{VS} 180^{\circ}\right)$, this term $\frac{F_{S}}{F_{a}}$ is always ignored.

Photoexcited electrons populate higher electronic states and cause electrochemical potential, which in return changes the emission rate. Equation 1.11 gives the generalized Planck radiation law, with $\Delta \mu$ as chemical potential, $F_{a}=\pi$ at surface with air. $\Delta \mu$ is equal to $q V$ when a voltage $V$ is applied to device.

$$
B_{e}(E, \Delta \mu)=\frac{2 F_{a}}{h^{3} c^{2}} \frac{E^{2}}{e^{\frac{E-\Delta \mu}{k_{B} T_{a}}}-1}
$$

Then the equivalent emission current density is

$$
j_{e m}(E, \Delta \mu)=q(1-R(E)) \varepsilon(E) B_{e}(E, \Delta \mu)
$$

$\varepsilon(E)$ is possibility of photon emission and remains the same as under dark in the premise that $\Delta \mu$ is constant across the devices, which is ready to be satisfied for high charge mobility.

\subsubsection{Efficiency Limit}

The net current density $j_{a b s}(E)-j_{e m}(E, \Delta \mu)$ could be divided into two parts, the net absorption contribution which is responsible for photocurrent and the net emission contribution which is responsible for the dark current.

$$
\begin{gathered}
J_{s c}=q \int_{0}^{\infty}(1-R(E)) a(E) B_{s}(E) d E \\
=q \int_{0}^{\infty} E Q E(E) B_{s}(E) d E \\
J_{e m}(\Delta \mu)=q \int_{0}^{\infty}(1-R(E)) a(E)\left(B_{e}(E, \Delta \mu)-B_{e}(E, 0)\right) d E
\end{gathered}
$$


In equation 1.15 and 1.16, no transport loss is considered. $\Delta \mu$ is equal to $q V$ when a voltage $V$ is applied to device with assumption of constant $\Delta \mu$ across device. If absorption is step-function and no reflection at all, then we can obtain the net current density as equation 1.17 , and further approximated to equation 1.18 with $E_{\mathrm{g}}-\mathrm{V} \gg>\mathrm{k}_{\mathrm{B}} \mathrm{T}$ which holds most time, then we reassemble equation 1.3 here.

$$
\begin{gathered}
J(V)=q \int_{E_{g}}^{\infty}\left(\left(B_{S}(E)-B_{e}(E, \Delta \mu)+B_{e}(E, 0)\right) d E\right. \\
J(V)=q \int_{E_{g}}^{\infty} B_{S}(E) d E-q \int_{E_{g}}^{\infty} \frac{2 F_{a}}{h^{3} c^{2}} \frac{E^{2}}{e^{\frac{E}{k_{B} T_{a}}}} d E\left(e^{\frac{q V}{k_{B} T a}}-1\right) \\
J(V)=J_{S c}-J_{0}\left(e^{\frac{q V}{k_{B} T a}}-1\right)
\end{gathered}
$$

The current is only a function of bandgap $E_{\mathrm{g}}$ and applied voltage. Then we can calculate the output power and get the maximum power point for each bandgap. The maximum efficiency then only depends on bandgap. For large bandgap, photo current is low, but the working voltage is high and for small bandgap, photocurrent is high, but voltage is low, therefore the optimum bandgap for high efficiency is neither large nor small. Figure 1.4 demonstrates the calculated efficiency at room temperature $300 \mathrm{~K}$ with assumption made above under AM $1.5 \mathrm{G}$ for different bandgap devices. The maximum $\eta$ is around $33 \%$ at $E_{\mathrm{g}}$ around $1.37 \mathrm{eV}$ and solar cells based on GaAs which has Eg of $1.35 \mathrm{eV}$ is approaching this number with $29 \% .{ }^{[2]}$ The limit can be increased by either increase the solar radiation and decrease the emission of device. This can be simply achieved by increasing solar temperature or decreasing temperature of devices. It is impossible to change the temperature of sun, we need find other more practically ways improve the solar radiation like enlarging the angular range of solar radiation $F_{s}$ by concentrating light or decrease the emission angular range $F_{a}$ like using of perfect reflectors on rear surface. Apparently, semitransparent devices are expected has lower efficiency. After absorption of photons, photons with higher energy than $E_{\mathrm{g}}$ can only deliver a potential of $\mathrm{V}$ and other energy is lost to heat, and the stronger the radiation, the more heat would be produced. To keep the devices in lower temperature than ambient also costs energy and therefore tradoff is needed. To make use of these excess energy, down-conversion can be introduced to 
convert high energy photon into more than one low energy photons (still higher than $E_{\mathrm{g}}$ ) or convert one high energy excited charges into more than one low energy excited charges.

$$
\begin{aligned}
& P=V * J(V) \\
& \eta=\frac{P_{\max }}{P_{s}}
\end{aligned}
$$

All the discussion above is based on several assumptions which are not true for a real solar cell. First in real solar cell, there is always reflected, transmitted light and absorption from contacts (parasitic absorption) which is not made use of by the active materials. Second, non-radiative recombination through traps is unavoidable. If recombination is radiative then emitted photons have chances to be re-absorbed but for non-radiative recombination, energy was lost to heat and can never be reused again. Last, the energy losses due to the resistance across the device related to charge transport, which reduces the possible delivered voltage and makes the $\Delta \mu$ is not constantly equal to $V$ across device.

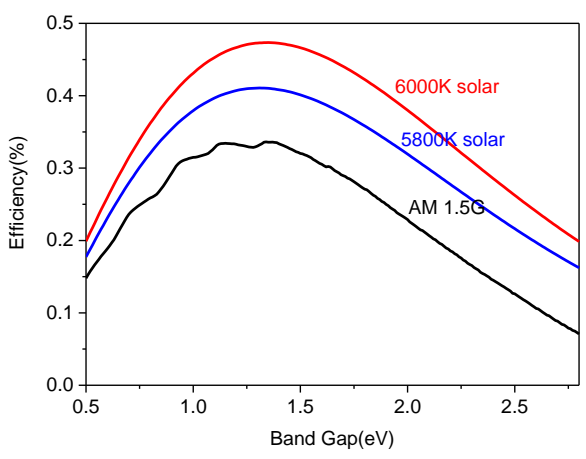

Figure 1.4. Theoretical efficiency limit for solar cells of single bandgap and step-like EQE under AM $1.5 \mathrm{G}$ and $6000 \mathrm{~K}$ solar without air mass consideration.

\section{Organic Solar Cell}

Organic semiconductors can be used to build solar cells, but unlike inorganic photovoltaic semiconductors, there is no rigid crystal lattice but a group of disordered molecules, either short or long. Therefore, organic semiconductors have quite different energetics and 
mechanism of charge generation, recombination and transport. In this chapter, basics of electronic structure of organic semiconductors are introduced and solar energy conversion with the help of organic solar cell is discussed following the knowledge presented in previous chapter.

\subsection{Energetics of organic molecules}

The main difference between an organic semiconductor and inorganic semiconductor is the molecules vs. atom constitution. In organic materials, the molecule is the basic element which might be short or long, with molecular weight varying from several Da to hundreds of kDa. The $\pi$-bonds in conjugated molecules or polymers determine the formation of energy band structure, which are highly related to the optical-electrical properties and which facilitate the delocalization of electrons along the conjugation. These molecular solids mostly are amorphous, with no order, polymers twisting as spaghetti, but some show semi-crystalline structure in solid. The inter-molecular packing would also change the energetics in the way as the intra-molecular packing. Therefore, morphology is critical for organic semiconductor devices. 


\subsubsection{Molecular Orbitals}<smiles>c1ccccc1</smiles>

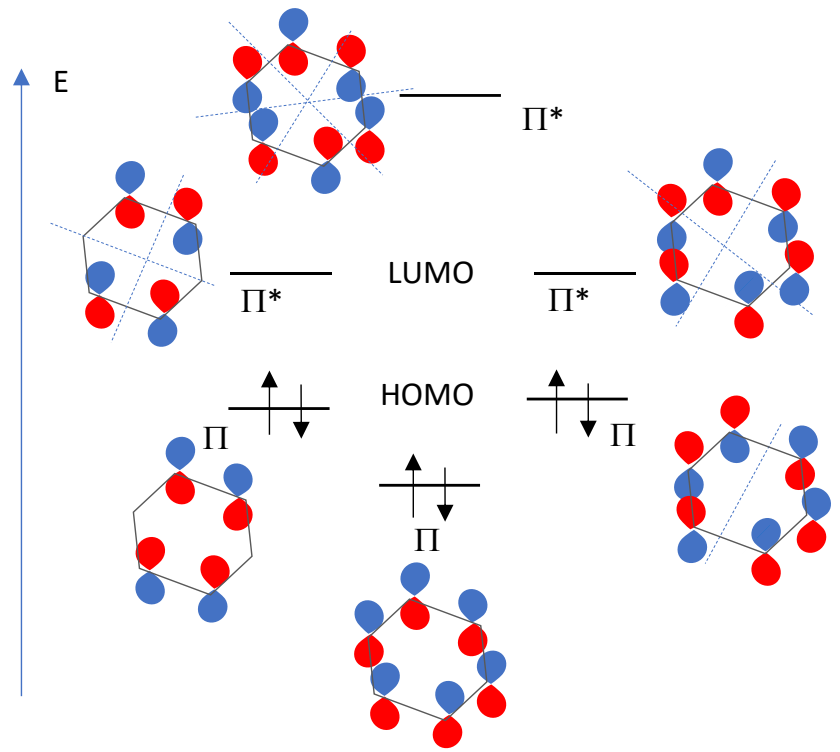

Figure 2.1 Kekulé structure of benzene and six energy levels, $3 \pi$-bonding (П) and $3 \pi$ antibonding $\left(\Pi^{*}\right)$, as a result of overlap of six $p_{z}$ orbital. With more nodes in the wavefunction, the higher energy. Due to the extended $\pi$-bonding along the ring and thus delocalization of $\pi$ electrons, these aromatic molecules are more capable of charge transport.

Most organic molecules have carbon atom as main component, and carbon has four valence electrons sited on $s-p$ hybrid orbital or $p$ orbital depending configuration. $\pi$ bonding or antibonding which depend the phase of the combination could be formed with overlap of these $p_{z}$ orbital orbitals and lead to splitting of energy levels. The bonding $(\pi)$ orbitals has lower energy than $\pi$ antibonding $\left(\pi^{*}\right)$ orbitals thus all the $\pi$ electrons occupy these $\pi$ orbitals in the first place. And the energy difference between the highest unoccupied molecular orbital(HOMO) and lowest occupied molecular orbital(LUMO) is defined as the bandgap of the material. All these $\pi$ electrons are not restricted on one atom but delocalized throughout all atoms that contribute to $\pi$ bonding. Figure 2.1 demonstrates the energy splitting resulting from $\pi$ and $\pi *$ 
bonding. Each $\pi$ bonding orbital up to HOMO accommodates one pair of electrons, with same energy but opposite spin. Electrons in lower energy orbitals can be excited to higher energy orbitals by absorbing photons with appropriate energy, corresponding to transition from ground state to excited state. The pair of electrons at both the ground state and photon-excited state preserve total spin $\mathrm{S}=0$ as singlet $\mathrm{S}_{0}$ and $\mathrm{S}^{*}$. Pair of two electrons with same spin compose a triplet, which is usually lower in energy than the singlet. Direct photon-assisted transition from ground state to triplet state is forbidden, but transition from singlet to triplet is possible through spin-orbital coupling, i.e. intersystem crossing.
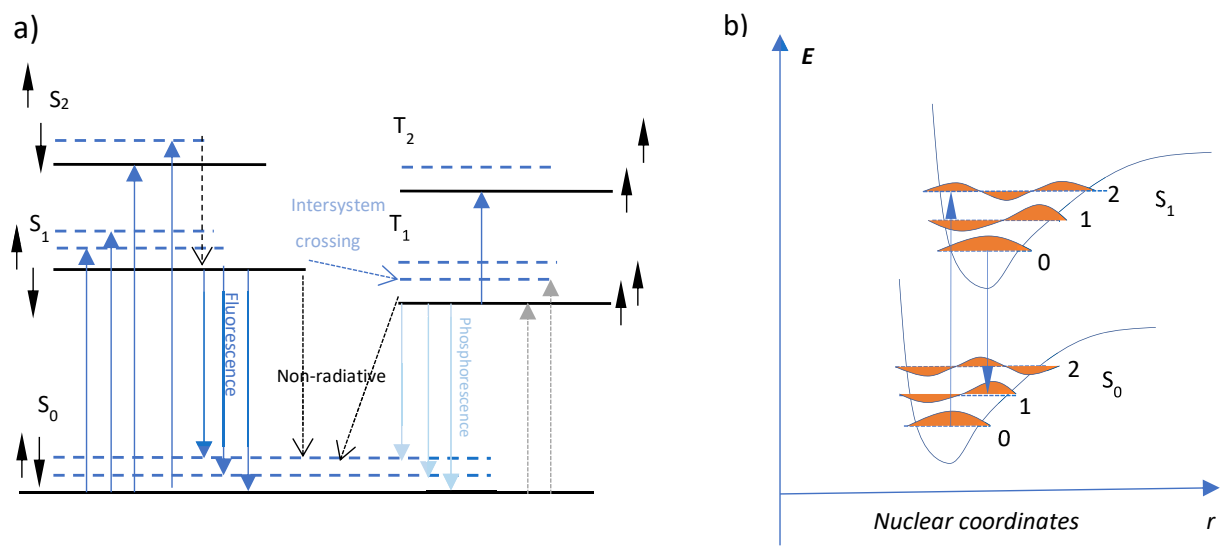

Figure 2.2 a) Scheme of singlet and triplet states, with vibrational manifolds (dashed line). b) Frank-Condon principle energy diagram, indicating that vertical transition is most favorable.

Higher excited states show short lifetime, tens of ps, and therefore quite soon relax to lowest excited state $S_{1}$, which has life time of ns then further decay to ground state with(radiative) or without (non-radiative) emitting a photon. The triplets lifetime is much longer usually in $\mu \mathrm{s}-\mathrm{ms}$, since it involves spin transition to ground state. Emitted photons have lower energy than the absorbed ones, causing the Stokes shift in luminescence spectrum, and the difference is a result of this fast vibrational relaxation. According to the Franck-Condon principle, the vibronic (vibrational and electronic) transition occur with little change of nuclear configuration, and the 
probability is determined by the overlap of vibrational wavefunction at ground state and excited state.

\subsubsection{Molecular Packing and Disorder}

Unlike when dissolved in in solvent with molecules separated from each other, inside a solid material molecules are usually aligned with each other or tangled together. The many forms and shapes of the same molecule hinders them to getting close to each other and hinders crystal formation. The interaction between organic molecules is then usually very weak, mostly through the van der Waals force, which means they have some degree of flexibility to move.

Organic amorphous aggregates possess geometrical distributions by nature, such as the distribution of intermolecular distance and relative orientation between adjacent molecules. Sometimes this is called structural disorder, to be distinguished from the energetic disorder originating from the electronic coupling discussed below. ${ }^{[3]}$ In a short range, ordered structure might be formed by molecular packing, like $\pi-\pi$ stacking. Inside this ordered crystal region, intermolecular interaction and slight overlapping of wave function leads to splitting of excitonic energy and broader excitonic band, resulting in narrower bandgap and more delocalization of charges and excitons. In addition, the polaronic effect is enhanced with more adjacent molecules, no matter in amorphous or crystal regions. As known, the presence of a charge would cause geometrical distortion of its surrounding molecules and this charge along with the surrounding distortion is called a polaron. Formation of polarons generates new polaronic energy states in the forbidden band, a bit away from HOMO and LUMO levels of unexcited molecules. The energy that it costs for the stabilization of the polaron is called reorganization energy, and time scale for stabilization is fast, around hundreds of fs. Figure 2.3 gives the visualization of the energy levels in single molecule and molecular aggregates. ${ }^{[4]}$

Co-existence of ordered and amorphous regions determines the energetics of organic semiconductor as disordered, with a wide distribution of energy states. In the context of organic solar cells, disorder plays significant roles in the charge transport, charge generation and recombination in many ways ${ }^{[5]}$. In the following chapters, more is to be discussed regarding disorder. 
The molecular flexibility on the other hand determines that organic aggregates have metastable structures, and under certain condition, transition could happen, probably from amorphous to crystal-like or vice versa. Then tuning of energetics for organic films is possible by changing morphology through simply thermal annealing.

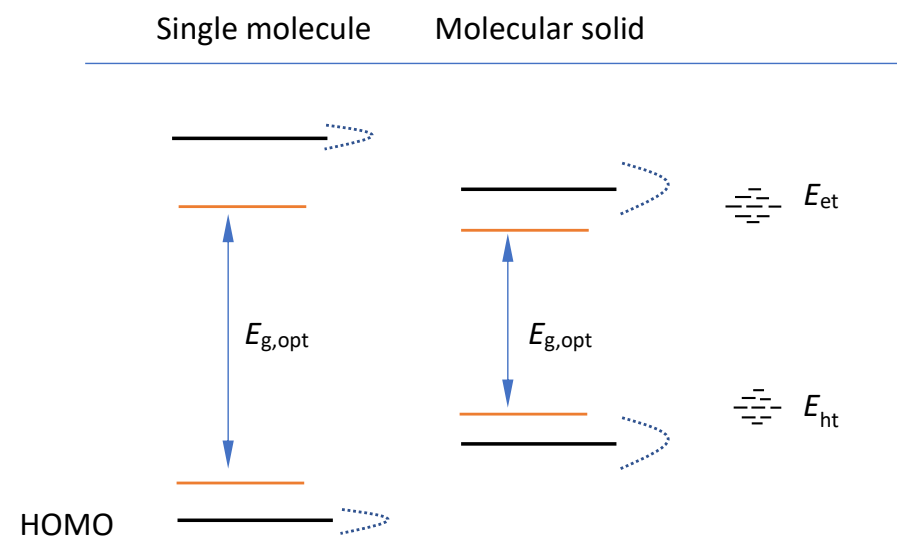

Figure 2.3 Comparison of energy levels between single molecule to molecular crystal. Optical bandgap is decreased because of two reasons, one is formation of ordered packing of molecules, and the other is formation of polaronic states. Charge moves at $E_{\text {et }}$ or $E_{h t}$ with broad distribution of energy, implying that energy loss during the transport might occurs.

\subsubsection{Charge Transport}

In amorphous materials, charges are usually localized on segments of a molecule and therefore they move not through band transport like in inorganic counterpart which is fast due to high delocalization, but through hopping between sites with distributed energies. Charge transport is indeed transport of polaron realized through the charge transfer from one site to another, which in theory could be predicted using the Marcus theory.

The most common model dealing with charge transport is Gaussian Disorder model(GDM), which introduce Gaussian shape of distribution for charge transport energy levels. Charges hop between these sites with rate of Miller-Abrahams type, which depends on inverse exponentials of both distance and energy difference of these two sites if charge jumps up to higher energy 
site. ${ }^{[6]}$ This model implies that charges have possibility to trapped into some states that either are spatially isolated or lower in energy, which then contribute negatively to charge transport. Apparently, this model simplifies the case and ignores the interaction of charges with its surrounding distortable molecules, i.e. the reorganization energy, and a more precise model should involve the Marcus theory. Except the lower energy states in the tail, the impurity and doping also introduce energy levels within the bandgap, or isolated sites, which as well act as traps.

\subsubsection{Exciton Diffusion}

In organic semiconductors, bound electron and hole pairs, i.e. excitons, are transported through Förster ${ }^{[7]}$ or Dexter transfer ${ }^{[8]}$. Excitons are electrically neutral and not affected by electrical field. Exciton transport is random and described in terms of diffusion. Since the amorphous nature of organic solid, in most cases excitons are localized and excitons diffuse by hopping between molecules in incoherent ways. In crystalline region, limited coherent transport could be also possible. Förster resonance energy transfer (FRET, or fluorescence resonance energy transfer) is a long range 1-10nm energy transfer with only energy transferred from excited donor (decay afterward) to acceptor (excited afterwards). It relies on dipole-dipole coupling and requires overlap of emission spectra of donor and absorption spectra of acceptor, which means from high energy site to lower energy sites are more favorable. Dexter transfer involves both energy and charge transfer, and it requires wavefunction overlapping of the donor and acceptor, thus only occur in short distance $<1 \mathrm{~nm}$. Triplet exciton diffusion operates through Dexter transfer for spin conservation during charge transfer.

Due to the disorder discussed in previous chapters, there is a broad distribution of available excited energy states and the structural disorder influences the dipole-dipole coupling. Migration of excitons from molecule to molecule or segment to segment of molecule is random. It could be downhill or thermally activated uphill in energy. Disorder cause the low and incoherent exciton transport, compared to coherent transport in highly ordered crystal, but meanwhile it might enhance the exciton mobility in microscopic regions and in early time scale. [9] 


\subsection{Basics of Bulk Heterojunction Solar Cell}

In Chapter 1, we have introduced basic working principles of a solar cells, and in this chapter, we will go further into a specific area as to organic solar cell. For organic solar cells, the bulk heterojunction $(\mathrm{BHJ})$ concept has promoted a big leap for the performance since $1995,{ }^{[10]}$ and until now, most study of organic solar are based on BHJ structure.

\subsubsection{Charge Generation}

To generate photocurrent, a solar cell needs firstly to absorb photons and create free charges, and then these charges be extracted by the electrodes. The first step is to create free charges, but it is not as easy for organic semiconductor to generate free charges after absorption of light as the inorganic semiconductor, since the dielectric constants are much smaller, which is usually 3-4 compared to $>10$ in inorganic material. This make the binding energy of electronhole pair much higher, $>0.3 \mathrm{ev}$ and dissociation possibility by thermal activation is then much smaller. However, it is found that at heterojunction interface, bound electron-hole pair, mostly called exciton in the context of organic solar cells, will engage in a fast charge transfer with electron or hole transferred to different molecules. The molecule giving out electrons or accepting hole is called donor and molecule accepting electrons or giving out holes is called acceptor. The driving force of charge transfer has been regarded as the LUMO difference of donor and acceptor, however recent study has demonstrated that minimal driving force is needed for efficient charge transfer to occur and some researcher has attributed reasons to delocalization. ${ }^{[11,12]}$ The excitons originally generated far away from the interfaces need to diffuse to the interface for charge separation. This diffusion is not efficient in most organic materials used for solar cells, and the idea to overcome this problem is the BHJ concept, mixing the donor and acceptor to maximize the interface areas and minimize distance to the interfaces for excitons. But the mixed phase is not favorable for charge transport considering the donor and acceptors have different mobility for holes and electrons. Only if the morphology can be well controlled so that the trade-off between charge generation and transport is found, then highest performance could be obtained.

All the steps involved have been mentioned above, and more details is to be listed below. 
- Absorption of photons. It is determined in the first place by the absorption coefficient of material in the films, to which morphology make a difference. The geometrical structure of the device also plays key role in causing parasitic absorption, which is the absorption of interlayers or electrodes other than active layer, because of the interference which varies with film thickness, interfaces and reflectivity of bottom electrodes ( $\mathrm{Al}$ or $\mathrm{Ag}$ ).

- Exciton diffusing to interface. The diffusion length is defined as $L_{D}=\sqrt{D \tau}$, where $D$ is the diffusivity and $\tau$ is the lifetime of excitons. The typical diffusion length is less than $20 \mathrm{~nm}$, which set a limit to for optimal domain size of pure phase. Disorder is mostly expected to decrease the diffusion length ${ }^{[13,14]}$ either by reducing the lifetime or the diffusivity.

- Charge transfer at interface. This process has high efficiency and time scale of fs. ${ }^{[15-17]}$ The back transfer is also possible, regenerating an exciton in donor or acceptor molecules. The offset of the LUMO or HOMO might play as a barrier for the back transfer, whereas the mechanism behind is still debatable.

- Charge separation. This process is critical since it determines how much free carriers you can get from the bound exciton, but not fully understood so far. The most accepted idea is that the charge separation occurs through an intermediate state -the charge transfer state (CTS) at the donor/acceptor interface. CTS is experimentally observable through absorption or emission spectroscopy. The charge separation from CTS is fast, in several ps. ${ }^{[18,19]}$ CT excitons is still coulombically bound electron-hole pairs, and the binding energy hinders further spatial separation of charges. A complete dissociation of this pair is thought as thermal-activated and field-dependent, but different arguments exist, and entropy and delocalization were introduced as alternative interpretations. ${ }^{[20,21]}$

- Charge transport. Once separated, the free charges move their way to the electrodes across the active layer. Holes and electrons move in donor domain and acceptor domain separately, but on the way, hole and electrons could meet again to form a bound pair and recombine afterward. In $\mathrm{BHJ}$ solar cell, this could be an issue since donor and acceptor usually mix so well as to create many interfaces where hole and electrons can meet. Ideally, the charge should reach the corresponding electrodes before they 
recombine or get trapped, therefore mobility is always a critical parameter to characterize. In thermal equilibrium condition, the transport is thought to be determined by the field and concentration gradient, the sum of which we call quasifermi level. But observations are supporting the argument that no thermal equilibrium is reached in some cases for organic solar cells and charges move much faster than that expected under the equilibrium conditions. ${ }^{[22-24]}$

- Charge collection. Charges are collected at the contact and ideally hole can only be collected at anode and electrons only at cathode side. If the contact does not have good selectivity, charges could be also collected at the wrong sides and cause surface recombination. If there is a barrier at a contact that hinders the charges to be collected, then charge might pile up near contact and cause space charges which in return slow down charge transport in the bulk. This kind of barrier is easily observed as presence of S-shape on I-V curves.

a)

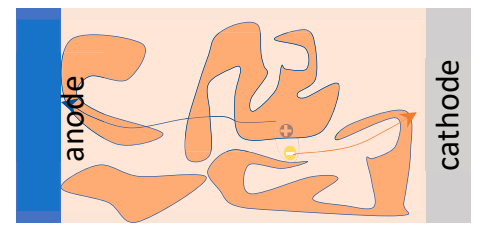

b)

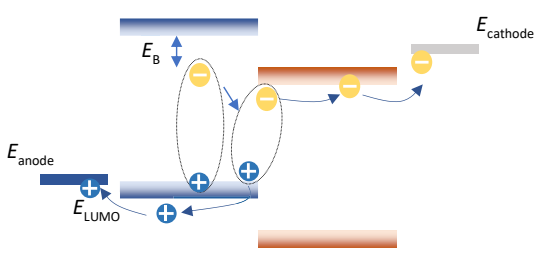

Figure 2.4 a)Diagram of BHJ concept. With donor and acceptor mixed and free charges are generated at the interfaces through CT state. Once charges are separate and moving to corresponding electrodes, hole and electrons might meet and recombine. b) Energy levels of solar cell. $E_{\text {homo }}$ and $E_{\text {lumo }}$ here are equivalent with hole transport level $E_{\text {ht }}$ and the electron transport level and $E_{\mathrm{et}}$ separately. $E_{\mathrm{B}}$ is the binding energy for excitons and needed to overcome for charges to be able freely moving at transport levels. Energy levels for electrodes are usually chosen close to the $E_{\mathrm{ht}}$ and $E_{\mathrm{et}}$, ideally forming ohmic contact for efficient charge collection. 


\subsubsection{Charge Transfer States}

The charge transfer state (CTS) is an intermediate state between excited donor or acceptor states and free carrier state. What roles CTS plays, and in which way so far, is debatable. But the introduction of the CTS concept has absolutely been a great success in investigating the charge generation mechanisms and understanding the open circuit voltage of organic solar cells. More details of relation between CTS and open circuit photovoltage are found in Chapter 3.

Figure 2.5 shows the state diagram and possible pathway of free carrier generation. Upon absorbing photons with energy $>E_{D^{*}}$, donor molecules form excited states $\left(D^{*}\right)$; excitons are created. The excitons have a binding energy which can be regarded as the difference between energy of the bound state and completely free charges. Excitons diffuse to the D/A interface and charge is transferred from donor( $\left.D^{*}\right)$ molecule to acceptor $(A)$ molecule. In the process of charge transfer, hot $\mathrm{CTS}_{\mathrm{CT}}{ }^{*}$ is first generated and then quickly relaxed to lowest $\mathrm{CT}$ state $\mathrm{CT}_{1}$ before dissociating to free charges. $\mathrm{CT}_{1}$ would be the precursor of free charges and photon emission. ${ }^{[25,26]}$ Excess energy is lost in this process and in fact not helping the charge generation. The binding energy to overcome from $\mathrm{CT}_{1}$ to $\mathrm{CS}$ is now unclear and debatable, might be higher or lower than thermal energy $k_{B} T$.

At $D / A$ interfaces, the free charges are generated with high efficiency with IQE $>90 \%$ for some systems ${ }^{[27-29]}$. According to some researchers, the distance between the electron and hole is 4 $\mathrm{nm}$ for P3HT:PCBM, which is corresponding to $100 \mathrm{mV}$ of binding energy, much higher than $k_{B} T$ in room temperature. ${ }^{[30]}$ Then this high efficient charge generation is therefore explained from points of view of entropy and delocalization. ${ }^{[12,21,31,32]}$ Very recently, there are reports that the binding energy of $\mathrm{CT}_{1}$ states have same order of thermal energy according to the quantumchemical modeling. ${ }^{[33]}$ Direct transition from ground state to excited CTS and radiative decay through excited CT state to ground states could be possible. Figure $2.5 \mathrm{~b}$ ) demonstrates the EQE spectra of TQ1:PCBM solar cell, the shoulder is the contribution from CT state manifolds with a Gaussian distribution. Figure $2.5 \mathrm{c}$ ) shows the extra peak from CTS which is red-shifted compared to the emission from the pure D or A. It should be noted that since the excited CTS are usually the lower in energy than excited states of D or A, the emission for CTS states has lower on-set voltage of electroluminescence and are preferable to formed by injected electrons 
and holes. However as mentioned before, the dissociation from $\mathrm{CT}_{1}$ states are highly efficient and the interfaces of donor and acceptor is limited. Thus both the emission or absorption of CTS are usually so low that only with highly sensitive equipment is it observable as extra peaks in absorption, EQE, photo-luminescence and electroluminescent spectra.

Decay from $\mathrm{CT}_{1}$ can be non-radiative, and in fact dominate over radiative decay in most cases of polymer/fullerene and polymer-polymer systems. Recently, it was unveiled that electronvibrational coupling in organic semiconductors that determines the low efficiency. Nonradiative transition occurs through $\mathrm{CT}_{1}$ to excited vibrational $\mathrm{GS}$ states, the coupling increased with $\mathrm{CT}_{1}$ energy decreasing and Vandewal at. al. attributed this to coupling mediated by the C-C bonds rather than $\mathrm{C}-\mathrm{H}$ bond. ${ }^{34]}$

a)
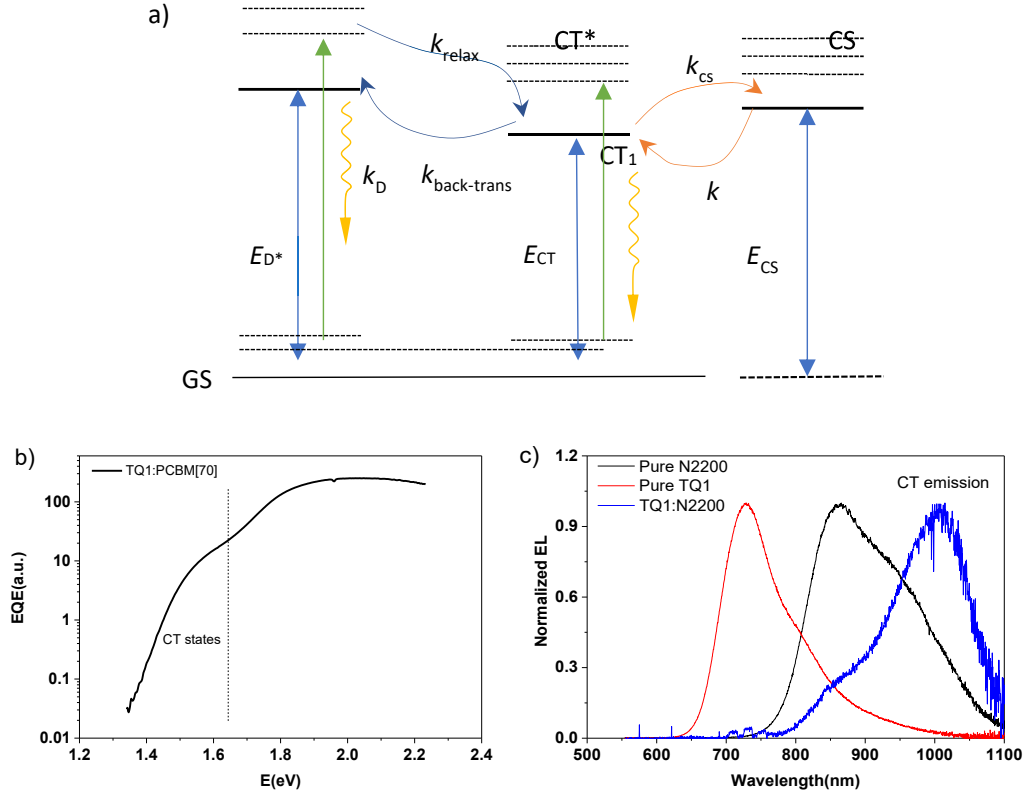

Figure 2.5 a) State diagram. $D^{*}$ is the donor excited states. $\mathrm{CT}_{1}$ is the lowest energy and fully relaxed charge transfer state. $\mathrm{CT}$ state has possibility $k_{\mathrm{cs}}$ to dissociate to free carriers(CS) and could back-transfer to D*. b) EQE spectrum for TQ1:PCBM blend device. The sub bandgap absorption (the shoulder) is attributed from CTS which obeys Gaussian distribution. c) electroluminescence from CTS and exciton states of donor( TQ1) and acceptor(N2200). 


\subsubsection{Recombination}

The simplest mechanism of recombination is direct band-to-band, or bimolecular type, from free charges, one hole and one electron. The probability is proportional to product of both charge carrier density, i.e. order 2 recombination. The recombination constant is usually described by Langevin theory. But recombination rate in many organic solar cells has been experimentally observed to be much lower than predicted Langevin recombination rates $R$. As a result, a reduction factor $\mathrm{m}$ was added to recombination constant to compensate deviations.

$$
R=\gamma\left(n p-n_{i} p_{i}\right), \gamma=m \frac{q\left(\mu_{n}+\mu_{p}\right)}{\varepsilon}
$$

$\gamma$ is proportional to the sum of mobility $\mu_{n, p}$ and inverse of permittivity $\varepsilon$ because in Langevin theory, it is assumed that hole and electron meet and capture each other, when they are close enough), the velocity of free charges increases the capture rate, but the screening ability of materials reduces it. The Langevin theory gives a simple equation with all parameters easy to determine, and it is widely used in modeling of organic solar cells. However, it is notable that free charges meet and form CTS first in BHJ solar cells, whereby the recombination rate is only used to describe the formation rate of CTS in typical modeling. ${ }^{[35]}$

Trap-assisted recombination, also known as Shockley-Read-Hall recombination, happens through states in the bandgap. In inorganic semiconductors, these traps could be introduced by impurity, dopants, or surface states. Trap states could capture both electron and holes and act as recombination centers.

$$
R_{S R H}=\frac{n p-n_{i}^{2}}{\tau_{n, S R H}\left(p+p_{t}\right)+\tau_{p, S R H}\left(n+n_{t}\right)}
$$

$\tau_{n, p, S R H}$ is the lifetime of captured electron or hole by traps which is the inverse of the charge velocity, capture cross section and trap density, $p_{t}=n_{i} \exp \left(\frac{E_{i}-E_{t}}{k_{B} T}\right)$ and $n_{t}=n_{i} \exp \left(\frac{E_{t}-E_{i}}{k_{B} T}\right) . E_{t}$ and $E_{i}$ are the single trap states energy and intrinsic Fermi level. For mid-bandgap $\operatorname{traps}\left(E_{i}=E_{t}\right)$, if the $\mathrm{n}$ and $\mathrm{p}$ are similar in magnitude (easily satisfied for $\mathrm{BHJ}$ solar cells under light )and with similar capture cross section, then $R_{S R H}$ reaches the maximum. If in a $\mathrm{p}$ type material in the context of inorganic materials, if $\tau_{n, S R H} p \gg \tau_{p, S R H} n$ and $p \gg p_{t}$, then it reduces to

$$
R_{S R H} \approx \frac{n}{\tau_{n, S R H}}
$$


Nevertheless, for organic materials, it is difficult to make these assumptions and extract these parameters when mixing donor and acceptor. Energy states at the tail of density of states (DOS) could also act as traps. Kirchartz addressed relationships between recombination order and DOS and found if the tail of density of states is largely extending into bandgap, then recombination rate is with order $1, R_{S R H} \propto n(p) .{ }^{[36]}$ Therefore, we would call trap-assisted recombination sometimes also as monomolecular recombination. Unlike bimolecular recombination, trap-assisted recombination is non-radiative which enables the detection of traps with electroluminescence measurements.

Geminate recombination is the recombination of bound electron-hole pairs, usually referred to a CTS pairs, generated from one photon-excitation. These bound pairs could either decay to ground states or dissociate into free charges. The possibility of dissociation is determined by electron-hole distance and field within the Onsager-Braun model. Combined with the bimolecular recombination rate for CTS formation, a full description of recombination in organic solar cells could be obtained. ${ }^{[35]}$ Although this model shows good agreement with experiment in some studies, it is still under debate and correction was proposed. ${ }^{[37]}$

In addition to recombination at the D/A interface in the bulk, recombination might occur through surface states at interfaces to the contact layers, typically PEDOT:PSS, $\mathrm{MoO}_{3}$ at anode and $\mathrm{ZnO}, \mathrm{LiF}$ at cathode. These interlayers are used to tune the work function and/or improving selectivity of the electrodes. Surface recombination is controlled by the concentration of excess minority $\Delta n_{\min }$ carrier near the contacts and the surface recombination velocity $S_{\text {min }}$,

$$
J_{s}=q S_{\min } \Delta n_{\min }
$$

Surface recombination velocity is proportional to density of surface states that are active in capturing charges. Severe surface recombination decreases carrier density near contact and bend the quasi-fermi level at contact which would reduce the $V_{\text {oc. }}$ In addition, under open circuit condition with weak internal field and diffusion dominating, reduced carrier density at contact lead to increased diffusion from bulk to contact which further lower the quasi-fermi level splitting. ${ }^{[38]}$ 


\section{Open circuit voltage of organic solar cells}

Open circuit voltage $\left(V_{\text {oc }}\right)$ for a solar cell is the output voltage when the net absorption equals net emission and net current is 0 . It is the highest voltage a solar cell can deliver, and positively related with the maximum power output of a solar cell. To get high power conversion efficiency, $V_{\text {oc }}$ should be maximized. Therefore, a model than can describe the $V_{o c}$ is highly significant. In this chapter, we will introduce some of these models and discuss the energy loss.

\subsection{Quasi-Fermi level splitting}

As discussed in Chapter $1, V_{\text {oc }}$ is a chemical potential, which can be regarded as quasi-fermi level splitting in solar cell. It assumes free charges are all generated the interface of donor and acceptor. Generated electrons are situated on LUMO levels of acceptor and holes on HOMO of donor. If these carriers are quasi-thermal equilibrium with a characteristic Fermi level, then we can determine carrier density with Boltzmann approximation by

$$
\begin{gathered}
n=N_{c} \exp \left(-\frac{E_{c}-E_{f n}}{k_{B} T}\right) \\
p=N_{v} \exp \left(\frac{E_{v}-E_{f p}}{k_{B} T}\right)
\end{gathered}
$$

Where $\mathrm{n}, \mathrm{p}$ are carrier density, $N_{\mathrm{c}}$ and $N \mathrm{~V}$ are the effective DOS at acceptor's LUMO and donor's HOMO separately, $E_{\mathrm{fn}}, E_{\mathrm{fp}}$ are the quasi-Fermi levels. Combining equation 3.1 and 3.2, we can get

$$
V_{o c}=E_{f n}-E_{f p}=\left(E_{c}-E_{v}\right)-k_{B} T \ln \left(\frac{N_{v} N_{c}}{n p}\right)
$$

where the quasi-Fermi level splitting is expressed by the carrier density at the interfaces, and the effective bandgap of the donor-acceptor mixture, $E_{g}^{D A}=E_{c}-E_{v}$. The quasi-Fermi level is meaningful only when an equilibrium is reached, and when connected with $V_{o c}$, which is measured as potential difference between anode and cathode, influences of charge transport from interfaces to corresponding electrodes and quasi-Fermi level bending at electrode contacts should be considered, but we will not explore details here.

When $T$ approaching $0, V_{o c}$ eventually becomes equal to the effective bandgap. Recombination and generation of charges determines the carrier density. For real organic solar cells, 
recombination parameter should be added along with generation rate $\mathrm{G}$ to replace $n p$ product for consideration of non-radiative recombination. The different order of different recombination will be present in $\mathrm{R}$ and $\mathrm{G}$ expressions and lead to different factors before the logarithmical part. In fact, the light intensity dependence of $V_{o c}$ was often measured to determine the factors according to equation 3.4. More details are found in chapter 5.

The effective DOS for inorganic semiconductors usually has a sharp edge, but this is not the case for organic semiconductors. Because of disorder, there is always a broad distribution of states in the DOS and indefinite bandgap for organic semiconductors. If we assume same Gaussian distribution of DOS for HOMO and LUMO, still with $E_{c}$ and $E_{v}$ as center, equation 3.4 is modified to ${ }^{[39,40]}$

$$
\begin{aligned}
V_{o c}=E_{f n}-E_{f p} & =\left(E_{c}-E_{v}\right)-\frac{\sigma^{2}}{k_{B} T}-k_{B} T \ln \left(\frac{N_{v} N_{c}}{n p}\right) \\
& =\left(E_{c}-E_{v}\right)-\frac{\sigma^{2}}{k_{B} T}-k_{B} T \ln \left(\frac{N_{v} N_{c}}{\gamma G}\right)
\end{aligned}
$$

where $\sigma$ is the standard deviation of Gaussian distribution, representing the disorder. Equation 3.4 gives linear correlation between temperature and $V_{o c}$, and in equation 3.5, disorder term has reciprocal correlation with temperature. Nevertheless, the disorder term apparently gets invalid when temperature decrease down to some extent, otherwise unreasonable infinity shows up. This limitation is that Fermi level should be more than $\frac{\sigma^{2}}{k_{B} T}$ below the $E_{c}$ or $E_{v}$ which is also temperature dependent to fulfill the requirements of Boltzmann distribution. ${ }^{[40]}$ Disorder $\sigma$ can be obtained through temperature-dependent mobility measurements, since as addressed in Chapter 2, there is correlation between disorder and charge transport. However, careful attention should be taken since local disorder at the very interface where donor and acceptor mix might vary with disorder in the pure domains where charges transport.

Equation 3.5 shows an unavoidable difference from effective bandgap to the $V_{o c}$. This loss comes from two sources, one is the disorder and the other reduced carrier density through recombination. Higher disorder makes more available states extended into bandgap, and free charges would prefer to stay in lower energy states if in equilibrium, whereas more carrier density means more chances of higher energy states occupied. Both influence the quasi-Fermi level splitting. To reduce this loss, smaller disorder and suppressed recombination are desired. 
It is also notable that bandgap is also temperature-dependent, not much for inorganic semiconductors with rigid crystalline structure, but considerably so for organic semiconductor with flexible molecules. All in all, this equation contains parameters that indeed are difficult to extract experimentally and is not helping quantify the temperature dependency of $V_{o c}$.

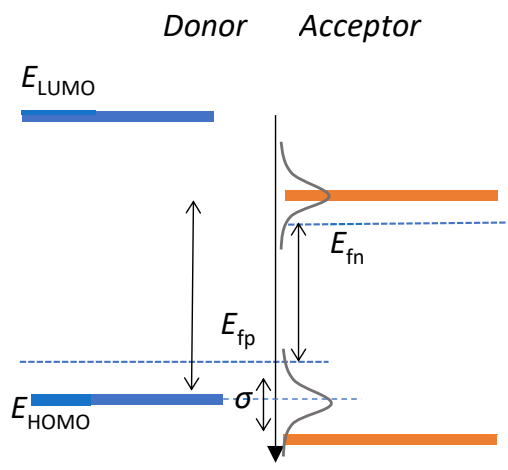

Figure 3.1 The quasi-Fermi level splitting at interface, and a Gaussian disorder of DOS. Disorder results in making the optical determination of bandgap difficult. Disorder also reduce the upper limit of $V_{o c}$.

\subsection{CT states and $V_{o c}$}

In Chapter 2, we have derived the current-voltage equation of a solar cell, equation 1.18, using theory of detailed balance. It is easy to get expression for $V_{o c}$ simply letting $J=0$,

$$
\begin{gathered}
V_{o c}^{r a d}=\frac{k_{B} T}{q} \ln \frac{J_{s c}}{J_{0}^{r a d}} \\
J_{s c}=q \int_{0}^{\infty} E Q E_{P V}(E) B_{s}(E) d E \\
J_{0}^{r a d}=q \int_{0}^{\infty} E Q E_{E M}(E) \frac{2 F_{a}}{h^{3} c^{2}} \frac{E^{2}}{e^{\frac{E}{k_{B} T_{a}}}} d E
\end{gathered}
$$

Where $E Q E_{P V}$ is the external quantum efficiency of solar cell, and the $E Q E_{E M}(E)$ is the probability of photon emission. Obeying the reciprocity relationship between the absorption and emission, $E Q E_{P V}(E)=E Q E_{E M}(E)$. ${ }^{[41]}$ The $E Q E_{P V}$ of a solar cell are experimentally measurable, and thus $V_{o c}$ can be calculated. These equations are only valid if all the 
recombination is radiative, and the obtained value of open circuit voltage is the radiative limit $V_{o c}^{r a d}$. But in real solar cells, especially the organic solar cells, non-radiative recombination always dominates over radiative recombination, meaning that emission scales with $\exp (V /$ $\left.n_{\text {rad }} k_{B} T\right)$. Under open circuit condition, only part of injected charges create photons and the ratio is $E Q E_{E L}$. Modification can be done to equation 3.7 by adding $E Q E_{E L}$ and $n_{\text {rad }}$ to equation 3.10. ${ }^{[41]}$ Comparing equation 3.7, the difference $\frac{n_{r a d} k_{B} T}{q} \ln E Q E_{E L}$ then is called nonradiative loss. ${ }^{[42]}$

$$
V_{o c}=V_{o c}^{r a d}+\frac{n_{r a d} k_{B} T}{q} \ln E Q E_{E L}
$$

From equation 3.7-3.9, the temperature dependence is not explicit, but $J_{0}^{\text {rad }}$ are indeed determined by ambient emission spectrum, which depends on temperature. The other important factor is the bandgap. As for most efficient solar cell, the bandgap is mostly designed to be less than $2 \mathrm{eV}$, which enables it to absorb most part of solar radiation. Changing of bandgap will change $J_{0}^{r a d}$ and $J_{s c}$ with same extent, if the bandgap edge is explicitly defined, either Gaussian or exponential distribution. But for BHJ solar cells, charge transfer states cause sub-band absorption which is seen as shoulder in absorption spectrum. This sub-band absorption is much lower than normal band-to-band absorption of donor or acceptor, therefore it contributes little to $J_{s c}$. However, because ambient emission has exponential dependence on energy, $J_{0}^{r a d}$ is heavily enhanced and affected by this sub-band absorption. From this point of view, the sub-bandgap CTS are determining $V_{o c}$ and presence of CTS sub-bandgap absorption do not improve $V_{o c}$.

On the other hand, we can expect that free charges energies would affect $V_{o c}$ as the carriers are eventually moved on charge transport energy levels and collected at these levels. CTS are only the intermediate states before charge separation and the correlation between CT energy and free charge energy is hard to determine. It seems hard to connect CT energy with $V_{o c}$, but Burke et al. suggested an equilibrium between CTS and free carriers can be reached, which was inspired by the reduced Langevin recombination rate observed in many organic solar cells. ${ }^{[43]}$ The reduced recombination rates can be interpretable if formation and splitting of CTS from free charges is much faster than the recombination rate through CTS. With an equilibrium, 
quasi-fermi level splitting of free carrier then is indeed equal to chemical potential of CTS. In this way, they connected the CTS with the $V_{o c}$.

Based on equation 3.10, Vandewal et al. ${ }^{[44,45]}$ derived an analytical equation correlating CTS energy to $V_{o c}$. The $E Q E_{P V}(E)$ for CTS are given according to Marcus theory,

$$
E Q E_{P V}(E)=\frac{f}{E \sqrt{4 \pi k_{B} T}} \exp \left(\frac{-\left(E_{C T}+\lambda-E\right)^{2}}{4 \lambda k_{B} T}\right)
$$

Where $f$ is a complex factor representing the electronic coupling and spatial density of charge transfer states, $\lambda$ is reorganization energy, $k_{B}$ is Boltzmann constant and $E_{C T}$ is the charge transfer states. Definition of $E_{C T}$ and $\lambda$ is shown in Figure 3.2. This equation has been successfully fitting the EQE curves of a solar cell, and through fitting , $\mathrm{f}, \lambda, E_{C T}$ can be obtained. Inserting equation 3.11 to equation 3.10 and approximation of replacing the full spectrum of EQE with CTS EQE when calculating $J_{0}^{r a d}$, finally we get equation connecting $V_{o c}$ directly with $E_{C T}$.

$$
\begin{gathered}
V_{o c}=\frac{E_{C T}}{q}+\frac{k_{B} T}{q} \ln \left(\frac{J_{s c} h^{3} c^{2}}{f q 2 \pi\left(E_{C T}-\lambda\right)}\right)+\frac{k_{B} T}{q} \ln \left(E Q E_{E L}\right) \\
q \Delta V_{\text {rad }}=-\frac{k_{B} T}{q} \ln \left(\frac{J_{s c} h^{3} c^{2}}{f q 2 \pi\left(E_{C T}-\lambda\right)}\right) \\
q \Delta V_{\text {non-rad }}=\frac{k_{B} T}{q} \ln \left(E Q E_{E L}\right)
\end{gathered}
$$

$q \Delta V_{\text {rad }}$ and $q \Delta V_{\text {non-rad }}$ are the radiative loss and non-radiative loss. For a certain pair of donor and acceptors with certain morphology, $f, \lambda, E_{C T}$ are fixed, then radiative loss is fixed. The photocurrent shows a logarithmical dependence, the same as previous result in equation 3.7. Temperature dependence is also given here, and $E_{C T}$ has been observed also linearly dependent on temperature. This temperature dependence is firstly explained more intuitively by the thermal enhanced vibration and torsion of organic molecules which reduces conjugation. ${ }^{[46,47]}$ But with CTS equilibrium theory mentioned above, we have an alternative explanation. As under equilibrium, Boltzmann statics is applicable and if we assume interfacial disorder cause distribution of $E_{C T}$ rather than one defined $E_{C T}$, e.g. Gaussian distribution $\sigma$, we can reformulate the CTS EQE equation 3.11 by replacing the $\lambda$ and $E_{C T}$ with equation 3.15 and 3.16 .

$$
E_{C T}=E_{C T}^{0}-\frac{\sigma_{c t}^{2}}{2 k_{B} T}
$$




$$
\lambda=\lambda^{0}+\frac{\sigma_{c t}^{2}}{2 k_{B} T}
$$

Where $E_{C T}^{0}$ and $\lambda^{0}$ is temperature-independent part. Experimental results fit the equation quite well, showing similar slope magnitude on plot over temperature. ${ }^{[43]}$

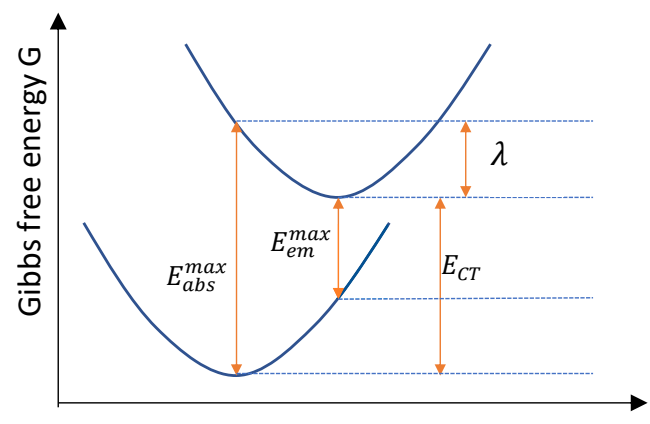

Reaction coordinate

Figure 3.2 Energy diagram for ground and excited charge transfer state.

\section{CTS Characterization}

In previous chapters, we have addressed the significance of CTS in organic solar cells and therefore a deep insight of CTS is needed. In BHJ solar cells, CTS situated at the D/A interfaces and its density is quite low. To observe CTS in absorption or emission, highly sensitive techniques are required.

\subsection{Fourier-Transform Photocurrent Spectroscopy}

Fourier-Transform Photocurrent Spectroscopy (FTPS) has been widely used to measure the EQE at sub-bandgap range. FTPS uses the output light beam of a Fourier-Transform Infrared (FTIR) spectrometer to illuminate the device, and the current response of devices is collected through a preamplifier. The high sensitivity of FTPS enables the observation of weak absorption in the sub-bandgap range. Response from a calibrated photodetector also need to be recorded, to 
calibrate data to the light beam irradiation. Its advantages compared to monochromatic EQE technique is high spectral resolution $(0.004 \mathrm{eV})$ between $800 \mathrm{~nm}$ and $400 \mathrm{~nm}$ and costing much less time. ${ }^{[48]}$

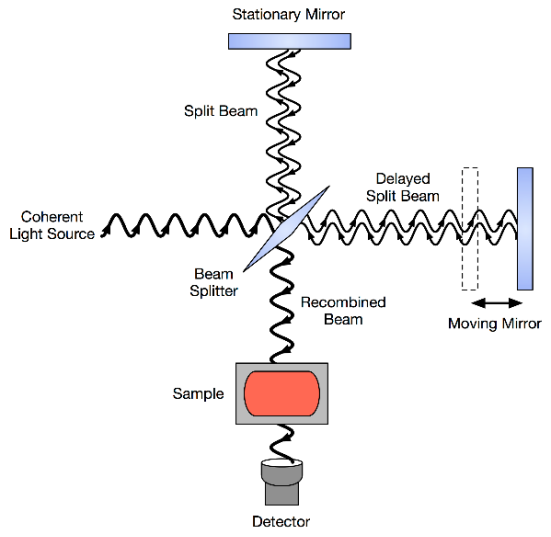

Figure 4.1 Schematic diagram of interferometer configured in FTIR, from Wikipedia.

Light beam of FTIR spectrometer is modulated through a Michelson interferometer by moving the mirror. Figure 4.1 shows diagram of interferometer configured in FTIR. Modulation frequency is determined by both the mirror velocity and wavelength of light. In continuous scan mode (CF-FTPS), incident light is modulated to frequency,

$$
f=2 \kappa v
$$

$\kappa$ is the wavenumber of light, $v$ is the mirror velocity. Through FTIR, the response of solar cell at each wavelength is translated to frequency response. For a mirror velocity of $0.1581 \mathrm{cms}^{-1}$, $632 \mathrm{~nm}$ light correspond to $5 \mathrm{kHz}$. Therefore, the ideal case for FTPS measurements is that devices have flat frequency response with cut-off frequency up to $20-30 \mathrm{kHz}$. But in most cases for organic solar cells, more than one scans with different mirror velocity are needed to correct for the non-flat frequency response. The velocity used in relevant work within this dissertation is $0.1581,0.3165,0.4747 \mathrm{cms}^{-1}$.

Figure 4.2 shows the measured FTPS EQE(black) and fitted curves using equation 3.11. EQE down to $10^{-5} \%$ can be measured. An obvious shoulder is present and through the fitting of the 
shoulder, $\mathrm{f}, \lambda, E_{C T}$ is obtained. Carefulness and experience are quite needed in choosing the fitting range, and the more obvious the shoulder, the easier and more reliable is the fitting.
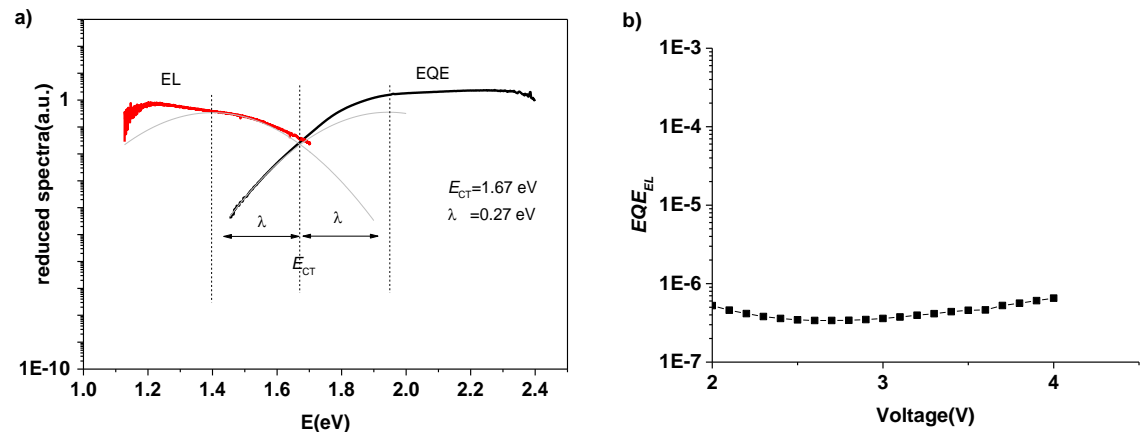

Figure 4.2 a) Reduced EL (red)and EQE (black)spectra with fitted curves(gray). Cross point is located at $E=1.69 \mathrm{eV}$ and fitted value of $E_{\mathrm{ct}}$ is $1.67 \mathrm{eV}$. b) Shows the $\mathrm{EQE}_{\mathrm{EL}}$ for the same device, corresponding to non-radiative $V_{o c}$ loss around $0.37 \mathrm{eV}$ by Equation 3.14.

\subsection{Luminescence spectroscopy}

\subsubsection{Photoluminescence}

Recombination through CTS states could be radiative; therefore, photoluminescence and electroluminescence measurements are quite useful in investing CTS. In photoluminescence, excitons are first photo-generated in both $D$ or $A$ domains and at $D / A$ interfaces. $D$ or $A$ excitons can decay to the ground state and emit photons. If excitons diffuse to interfaces before the decay, CTS excitons are generated and decay afterwards. CTS emission then appear as new peaks, red-shifted from the emission peaks of D or A. Meanwhile since the emission efficiency from CTS are much lower compared to that of pure D or A, a photoluminescence quenching in D/A blend is usually observed, which is highly depending on the morphology of the films. ${ }^{[49,50]}$ More quenching means more excitons diffuse to interfaces, which usually means small pure phase domains. The tricky part of the identification of CTS from photoluminescence is that for some systems, the emission from $\mathrm{D}$ or $\mathrm{A}$ is not avoidable and sometimes strong enough to drown CTS emission, due to serious phase separation. Additionally, when the emission from 
CTS lie in the tail of D or A emission, no obvious peak or even no obvious shoulders can be observed, because of the overlap.

\subsubsection{Electroluminescence}

Under positive voltage under dark, charges are injected into the device. Injected holes and electrons create excited states, and then must recombine, radiatively or non-radiatively. The emission is correlated with the applied voltage as mentioned in Chapter 3. By increasing the voltage, different energy states with corresponding chemical potential are populated. Since the CTS are the lowest energy states, they are first emerging when increasing the applied voltage. In this way, we can distinguish CTS emission from D or A emission, which is a big advantage compared with PL. Figure 4.3 a) shows the electroluminescence from the pure polymer(TQ1 as donor, and N2200 as acceptor) and the blend (D:A ratio 2:1). New peaks are found, and the peak position changes after thermal annealing, which could be evidence implying the morphological changes. These new peaks would be pronounced even under high voltage, that is high enough to start emission from pure polymer as shown in Figure $4.3 \mathrm{~b}$ ) and c). The recombination preferably occurring through CTS might be due to good mixing of donor and acceptor and no good connected pathway across the device formed via pure polymer domains. In addition, charges lose their energy on the way to lower energy levels before they eventually meet, which is favored by structural and energetic disorder. It also results in a bit of red-shift of CTS peak in EL compared to that in PL. EL spectra usually can reflect how is the morphology evolving after some treatments. With more emission from $D$ or $A$, big domains of pure polymer are expected.

The emission spectra of CTS has reciprocal relationship with absorption and from the line shape of emission, we can fit the $E_{C T}$ as we do from EQE spectrum. The emission rate at photon energy $E$ per unit energy ${ }^{[51,52]}$ is

$$
\frac{I}{E}=\frac{f_{e}}{\sqrt{4 \pi k_{B} T}} \exp \left(\frac{-\left(E_{C T}-\lambda-E\right)^{2}}{4 \lambda k_{B} T}\right)
$$

Where $f_{e}$ is the square of the electronic coupling matrix element, $E_{C T}$ and $\lambda$ are CTS energy and reorganization energy. The right-hand side is called the reduced emission spectrum, and likewise we can have reduced form of EQE spectrum by multiplying $E$ on both sides of Equation 
3.11. Reduced emission and EQE spectrum should have same line shape, but different central positions.

The cross point of these two spectral curves is just at $E=E_{C T}$, allowing us to determine the $E_{C T}$ or to cross check whether our fitting on EQE curves reliable. Figure 4.2 gives an example of how to determine CTS parameters using reduced EQE and EL spectra. The cross point at $1.69 \mathrm{eV}$ is quite close to the fitted $E_{C T}=1.67 \mathrm{eV}$ from CTS EQE data.
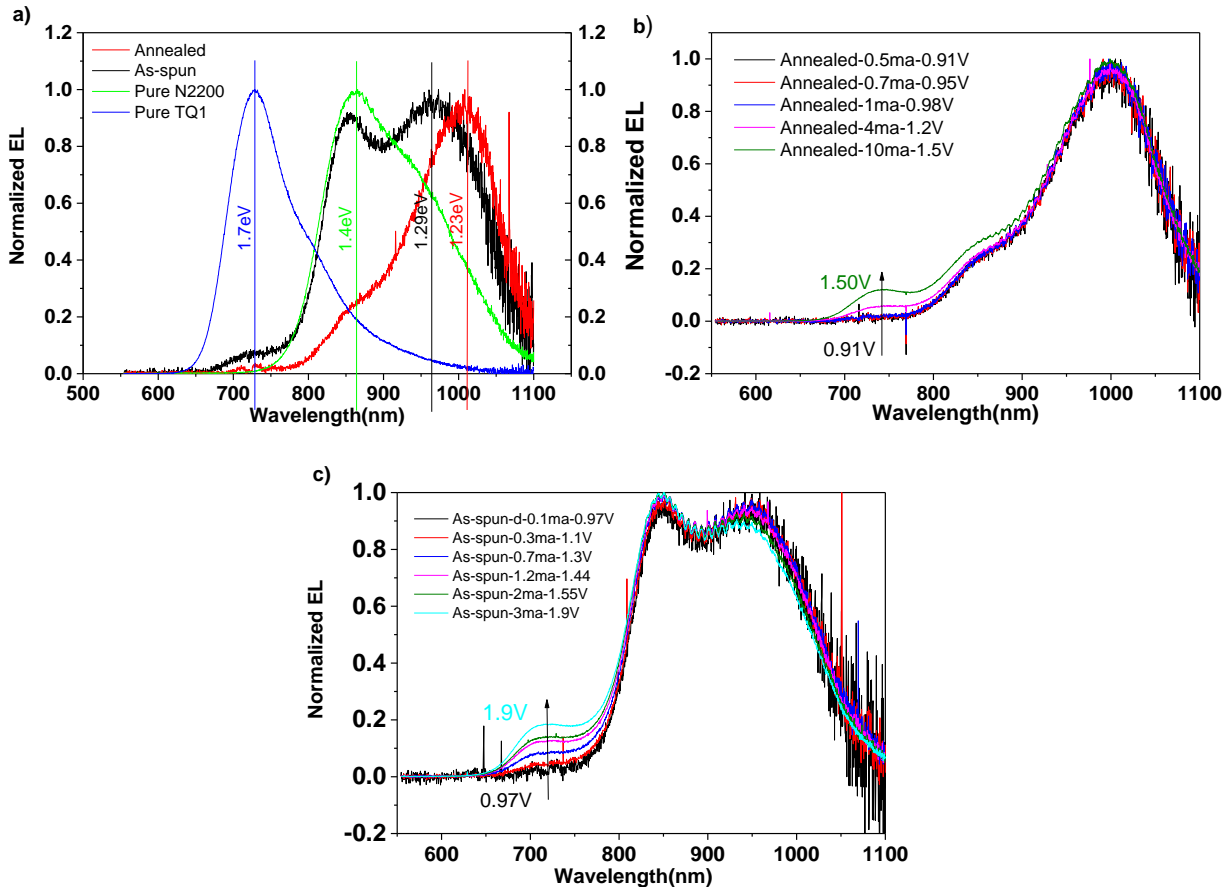

Figure 4.3 a)EL spectra of pure polymer TQ1 and N2200 as well as the blend with and without thermal annealing. After thermal annealing, CTS emission is red-shifted and further away from the peak of N2200. In as-cast blend, CTS emission are well overlapped with N2200 emission, with close peaks. b) and c) show the EL under increasing voltage. The spectra are almost maintained, even with one order of magnitude higher injection currents, only with minor increasing of pure polymer emission. 


\section{Recombination Related Measurements}

We have introduced the different mechanisms in organic solar cells in Chapter 2. Usually all recombination types co-exist in organic solar cells. Identifying the recombination intensity quantitatively is always difficult, but identification of the dominating recombination mechanism is easily done through some simple measurements. This can provide useful information to some extent.

\subsection{Light Intensity Dependence}

All recombination relies on free charge carrier density, and light intensity determines the charge carrier generation rate and carrier density upper limit. Changing the light intensity then change recombination rate and since bimolecular and monomolecular mechanisms have different reaction order, different behavior is expected with each type dominating.

Under short circuit condition, with high enough built-in field for an efficient organic solar cell, most generated charges can be extracted from the bulk, with little loss from recombination and the relationship between short circuit photocurrent J and light intensity $I$ can be found as $J \propto$ $I^{\alpha}$, where $\alpha=1$ to high accuracy. A deviation from that relation indicate severe bimolecular recombination or space charge effect. ${ }^{[53,54]}$ Figure 5.1 shows two different cases, one with a) $\alpha=1$ and b) $\alpha=0.95$. Figure $5.1 \mathrm{a}$ ) is comparison between the annealed and as-spun devices, and both devices shows almost no recombination and no space charge affecting. The other compares different structures with same material system, showing loss under short circuit condition.
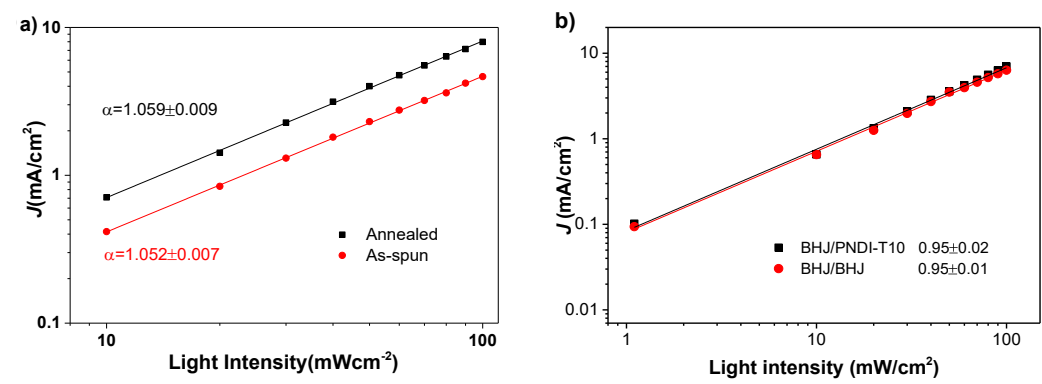
Figure 5.1 Light intensity dependence of short circuit current, in two systems. a) Comparison of annealed and as-spun devices from Figure 7(a), Paper 1. b) Comparison between different structures, from Figure 3(a), Paper 2.

Under open circuit conditions, all photogenerated charges recombine. From equation $3.4, V_{\text {oc }}$ depends on the carrier density product, which eventually relies on the generation rate and recombination rate. But bimolecular and monomolecular recombination have different reaction order, and lead to different $V_{\text {oc }}$ dependence on light intensity. If bimolecular recombination is dominating, then the semi-log $V_{\text {oc }}$-light intensity plot obeys a slope of $1 k_{B} T / q$, and if trapassisted recombination is dominating, then a slope of $2 k_{B} T / q$. If the two recombination are competing, the slope would be between 1 and $2 k_{B} T / q$. Figure 5.2 a) gives two devices with different slopes, $1.36 k_{B} T / q$ for annealed device and $1.61 k_{B} T / q$ for as-spun devices, implying more trap-assisted recombination in as-spun devices.

In some cases, there is no uniform slope over the full range, and transitions are observed where the slope changes. Kirchartz has studied the light intensity dependence of $V_{o c}$ and proposed that by analyzing the slopes as function of $V_{\text {oc }}$, more detailed interpretation of data can be given. ${ }^{[55]}$ Under different $V_{\text {oc }}$ range, the dominant recombination mechanism might vary and thus gives different slopes, with slope one for bimolecular and slope two for trap-assisted recombination. When the $V_{\text {oc }}$ gets close to $V_{\mathrm{bi}}$, the dominating surface recombination would make the slope approach 1 , or even lower than $1 .^{[36,56]}$ The reason is that as $V_{\text {oc }}$ gets closer to $V_{\mathrm{bi}}$, the minority carrier density close to the contacts increases with illumination intensity, but because the reduced selectivity due to low internal electric field, it would contribute less to $V_{\text {oc. }}{ }^{[57]}$ The same reasoning also applies to trap-assisted recombination if it mostly occurs close to contacts, which makes it also $V_{\text {oc }}$-dependent.

Figure 5.2 b) gives an example showing $V_{\text {oc }}$-dependent slopes from Paper 2 . For the BHJ/PNDIT10, the slope is even $<1 k_{B} T / q$ at high $V_{\text {oc }}$, but in the other part almost maintain $1 k_{B} T / q$. Therefore, not much trap-assisted recombination is present, but the surface recombination is a problem under one sun light intensity. The built-in potential is limited by the contacts and is not much higher than $V_{\text {oc. }}$ For the $\mathrm{BHJ} / \mathrm{BHJ}$ device, the slope is up to $1.57 k_{B} T / q$ at high $V_{\text {oc }}$ range, 
indicating increased trap-assisted recombination under reduced internal field. It also might imply trap-assisted recombination mostly occurring near both contacts.
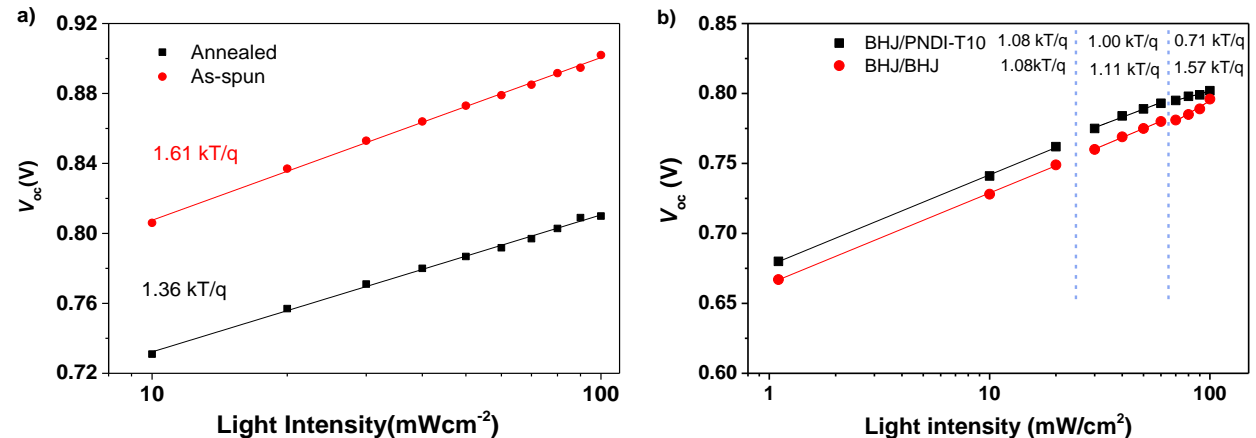

Figure 5.2 a) comparation between annealed and as-spun devices with same blend and device structure. b) comparation between devices with different device structure.

\subsection{Surface Velocity Determination}

Surface recombination sometimes plays important roles and is always connected with selectivity of contact layers, as for an electron contact interlayer, with higher hole surface recombination velocity, the electron selectivity is lower. Surface recombination velocity can be characterized by charge extraction by linearly increasing voltage (CELIV), in a novel method developed by Österbacka et al. ${ }^{[58,59]}$ If the surface recombination velocity $S_{R}$ is much smaller than the transport velocity $U_{d}=\mu E$ in the active layer, then carriers would accumulate at the interface and steady state current would be determined by surface velocity $J_{D}=q S_{R} p_{s}$, where $p_{s}$ is carrier (hole) density at interface. With $p_{s}$ as boundary condition, solving the Poisson equation and continuity equation, a relation between total charges $Q$ in the active layer and $S_{R}$ could be obtained, where $\mathrm{k}$ is Boltzmann constant, $\mathrm{T}$ is temperature, and $\varepsilon$ is permittivity.

$$
Q=\sqrt{\frac{2 \epsilon \epsilon_{0} k T J_{D}}{q S_{R}}}
$$

The total charges are ready to be fully extracted using CELIV when there is little recombination loss in the active layer, like in single carrier devices consisting of pure donor material. To make measurements easier, thick active layers $>300 \mathrm{~nm}$ is usually needed to hold more extractable charges. 
The $J(\mathrm{t})$ contains two parts, one is the displacement current $J_{0}$ due to changing voltage and the other is the extraction current of excess charges. Displacement current is determined only by the devices thickness and rate of voltage change. Unlike Photo-CELIV, the excess charges are injected rather than photo-generated, as a result with more injection current more excess charges would be present in devices. Therefore, devices must have good injection at one contact and the selectivity of the other contact is to be tested. It is notable that to make equation 5.1 valid, the surface velocity must at least be comparable with diffusion velocity $u_{d} \approx$ $\mu \mathrm{k}_{\mathrm{B}} \mathrm{T} / q d$, which means the velocity with no field, only relying on diffusion.

Figure 5.1 shows transient current of two different structures devices from Paper 2, A: PEDOT/TQ1(600 nm)/PEI/PEDOT and B: PEDOT/TQ1(900 nm)/PNDI-T10(4 nm)/PEI/PEDOT. When $V>V_{\text {bi }}$ (work function difference between anode and cathode), holes can be injected from PEDOT anode side and then collected at cathode PEI/PEDOT side. The bulk transport would be same for both structures but with different surface recombination velocity.

For structure $B$, the extracted $Q$ is 1.5 and $3.7 \mathrm{C} / \mathrm{m}^{2}$, and calculated $S_{R} \sim 0.022 \mathrm{~cm} / \mathrm{s}$ using equation 2. There are also chances for electron being injected from PEI side in both structure $A$ and $B$, but in structure $A$ the electron injection would be much less favorable due to the mismatch of energy levels with TQ1. For structure B, the electrons injected into PNDI-T10 domain would recombine with holes near cathode, reducing the extractable charges in devices and as a result the surface recombination rate of holes could be overestimated. Calculated $S_{R}$ is comparable with $U_{\mathrm{d}} \approx \mu \mathrm{kT} / q d=0.020 \mathrm{~cm} / \mathrm{s}$, and much smaller than drift velocity $U_{\mathrm{d}}=\mu E=0.076$ $\mathrm{cm} / \mathrm{s}$ under injection condition assuming $V-V_{\mathrm{bi}}=0.1 \mathrm{~V}$. No featured extraction current is observed in structure $A$, even under higher applied voltage, and thus higher injection current. Surface recombination velocity then is too high to prevent holes leaving the devices from cathode contact in structure A, much higher than bulk transport velocity. Adding a thin layer of PNDI-T10, which is supposed to be partially or even fully mixed with TQ1 after lamination, however could dramatically diminish the collection of holes at PEI/PEDOT. The high surface recombination is probably because of the mismatching work function of PEI/PEDOT with TQ1 HOMO, and the adding of n-type PNDI-T10 with HOMO lower than TQ1 will act as a blocking layer. On the other hand, electron traps close to cathode would also enhance the surface 
recombination by reducing the electron mobility according to Würfel et al., ${ }^{[60]}$ that selectivity of electrodes strongly depends on the difference between the mobility of majority and minority charge carriers in the vicinity of contact.
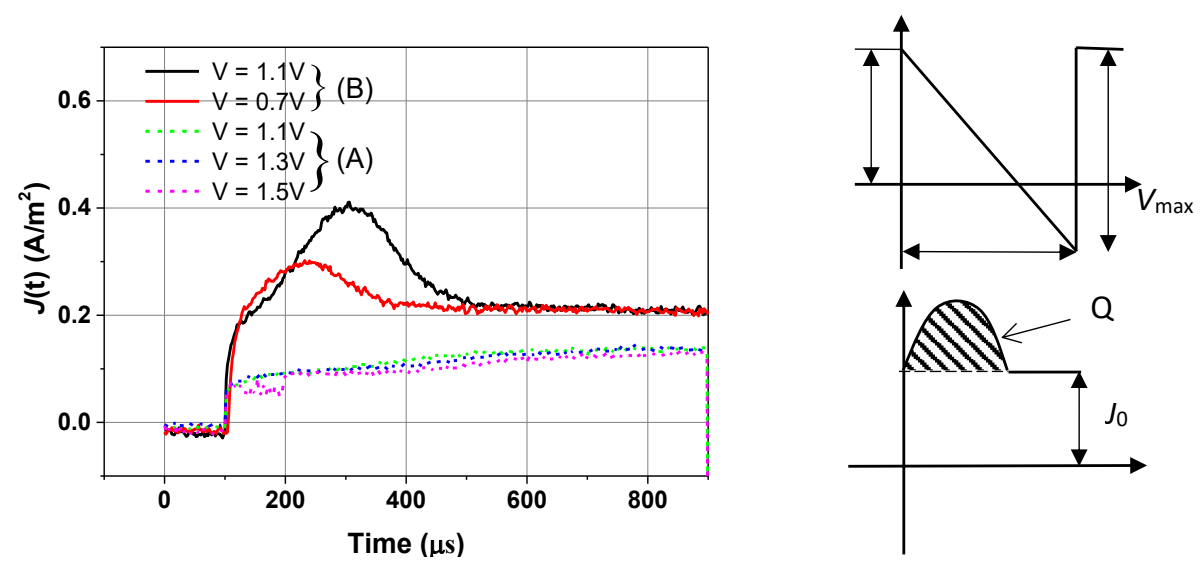

Figure 5.1 Schematic of CELIV technique is shown. $J(\mathrm{t})$ has been corrected for steady state current $J_{D}$ and total charges could be obtained from $Q=\int_{0}^{t_{\text {extr }}}\left(J(t)-J_{0}\right) d t$, where $J_{0}=\frac{\epsilon \epsilon_{0}}{d} \frac{d V}{d t}$, d is the thickness of active layer. For all different $V$, ramping rate of voltage is same. $J_{D}$ for structure $B$ is 0.033 and $0.18 \mathrm{~A} / \mathrm{m}^{2}$ at $V=0.7 \mathrm{~V}$ and $V=0.9 \mathrm{~V}$. $J_{D}$ of structure $A$ is $0.065,0.097$ and $0.148 \mathrm{~A} / \mathrm{m}^{2}$ for $V=1.1 \mathrm{~V}, V=1.3 \mathrm{~V}$ and $V=1.5 \mathrm{~V}$. With different voltage, injection current varies a lot, thus accumulated charges would vary.

\section{All-polymer Solar Cells Through Lamination}

Organic photovoltaics (OPV) have attracted attentions for their potential of being inexpensive, lightweight, flexible and suitable for roll-to-roll production. Contributed by numerous improvements on device structure and novel materials design by the organic photovoltaics community, since 1995 when the first efficient BHJ OPV was reported by Heeger, PCE has been increased dramatically from $3 \%{ }^{[10]}$ to very recently $12-17 \%{ }^{[61-64]}$. OPV has shown the potential of being as efficient as silicon solar cells (20\%), and what is more attractive is their flexibility, low cost, low weight and semitransparency. 
In OPV community, considerable attention has been focused on new acceptor materials, either polymeric or small molecules, to replace the once dominating fullerene derivatives such as $[6,6]$-phenyl- $\mathrm{C}_{71}$-butyric acid methyl ester $\left(\mathrm{PC}_{71} \mathrm{BM}\right)$. There are obvious disadvantages of fullerene derivatives as acceptor, like thermal instability, weak absorption in visible light range, poorly tunable energy levels and high cost. Novel alternative acceptors, with more morphology stability, more optical absorption and more desired energy levels have been reported. ${ }^{[65-68] ~[69,}$ 70] So far, all the top efficient OPV are using non-fullerene acceptors, which seem to lead the future of OPV.

Among these non-fullerene acceptors, polymer acceptor has shown several potential advantages:1) Conjugated polymers can be designed to have enhanced absorption coefficients, 2) The structural variations that can be created in polymers provide ways of fine-tuning the energy levels; 3 ) It is possible to tune the viscosity of the solution and thus film-forming properties, which is important for large-scale process;4) Conjugated polymers are potentially stable and cheaper; $\left.{ }^{[71]} 5\right)$ All-polymer solar cells have advantages in terms of robustness for flexible applications. ${ }^{[72,73]}$

Among various polymer acceptors, naphthalene diimide (NDI)-based polymers have favorable characteristics such as high electron mobility and suitable energy level as an acceptor relative to many donor polymers. ${ }^{[74-78]}$ An instance of the NDI-based polymer is poly-[ N, N'-bis(2octyldodecyl)-naphthalene-1,4,5,8-bis(dicarbox-imide)-2,6-diyl]-alt-5,5'-(2,2'-bithiophene) (P(NDI2OD-T2), Polyera ActivInk N2200). It has an electron mobility up to $\sim 0.85 \mathrm{~cm} 2 \mathrm{~V}-1 \mathrm{~s}-1$ and similar energy levels with PCBM. ${ }^{[79]}$ So far the best reported PCEs of all-polymer PSC was obtained with NDI-based polymers as acceptor. ${ }^{[76,80]}$

As the efficiency is progressing year by year, more and more groups has focused on printability for non-fullerene solar cells, i.e., using blade coating or spray coating to get same or higher PCE compared to the spin coating, implying the great potential for large area production in the future. ${ }^{[81-86]}$ However, some of them still use vacuum-based processing, usually to deposit Al or Ag electrodes, and some of them use indium tin oxide (ITO) with rare and expensive element indium, which could limit the large scale production of OPV. To meet the basic requirements for roll- to-roll printing that all the layers of OPV can be printed, high conductivity PEDOT:PSS has 
proved be a good alternative as semitransparent electrode, not only as charge carrier collector but also as hole selective layers because of its high work function. ${ }^{[86-88]}$ By tuning the work function of PEDOT:PSS with another layer, such as zinc oxide ( $\mathrm{ZnO})$ or polyethyleneimine (PEI), it can also work as a cathode. However, the wet deposition of a top PEDOT:PSS layer on the active layer allows wet PEDOT solution to penetrate to the bottom through defects in the printed layer, which may result in short-circuiting by direct contact to bottom electrodes. We have developed a lamination method to avoid this problem. ${ }^{[89]}$ By laminating two electrodes, both with active layer on top, we can build well-performing semitransparent solar cells on flexible substrates. This lamination process also provides us more possibilities of design of the active layer, since the two active layers on cathode or anode side may be different and could be a blend or a pure donor or acceptor, which also enable us to optimize device performance and study the lamination process in terms of morphology and electrical properties. Figure 6.1 shows all-polymer semitransparent solar cells fabricated through lamination, in which all the layers including the substrates are polymers, with structure PET/PEDOT:PSS/Active layer/PEI/PEDOT:PSS/PET.

The highest PCE we achieved so far is $2.3 \%$ from the PTB7-Th: PNDI-T10 system. As electrodes, PEDOT:PSS are not competitive compared to the typical evaporated ones, but it is still one of the most practical and low-cost candidates as electrodes so far for roll-to-roll printed organic solar cells.

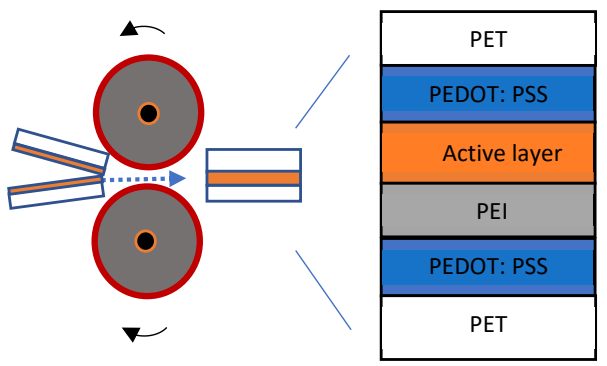


Figure 6.1 Diagram of lamination process for fabrication of semitransparent solar cells. The roller of laminator is heated up to $120^{\circ} \mathrm{C}$. Laminated active layers show good mechanical and electrical binding.

\section{All-polymer Photodetector}

\subsection{Introduction}

Photodetectors (PD) which can convert light into electrical signals have been highly influencing our modern society and are widely used in various fields such as image sensing, optical communication, biomedical sensing, environmental monitoring, and more [90-94] To date, mainstream PDs are composed of crystalline inorganic semiconductors due to their excellent charge carrier mobility, highly efficient charge generation and high stability. However, for inorganic photodetectors, tuning the spectral response range is a challenge and the production cost is another issue. ${ }^{[95]}$ Organic semiconductors are also appealing for light detection applications, just like to the organic photovoltaics(OPV), organic light-emitting diodes(OLED), or organic field-effect transistor(OFET). The detection region of organic photodiodes (OPDs) can extend from UV to near-infrared (NIR), and it can be panchromatic or selectively tuned to specific wavelength range. The capability of solution processing and roll-to-roll printing makes large area production with low cost possible. Moreover, the flexibility makes it possible for innovative applications such as curved large area imagers for X-ray detection in medical applications. ${ }^{[96,97]}$

Photodetectors can be divided into three sub-categories: photodiodes, photoconductors and phototransistors. The photodiodes can directly convert light into extractable charges and generate photocurrent. In photoconductors, conductance of photoactive materials can be changed after absorption of light, and for phototransistors conductance of channel between source and drain can be controlled by light absorption. In this paper we focus on the photodiodes.

Efficient organic photodiodes (OPDs) with bulk heterojunction concept were first reported between 1990-2000 by different groups [10,98-100], and since then numerous successful OPDs with response range from UV to near NIR light have been reported ${ }^{[95,101-106]}$. Photodiodes can 
work both as solar cells and photodetectors. But different to solar cells, the aims of photodetectors are to deliver a photocurrent signal rather than to deliver electric power. The power delivery requires both photocurrent and photovoltage, while for signal delivery photocurrent is mainly concerned. As such, external quantum efficiency (EQE) rather than power conversion efficiency is more important for a photodiode type photodetector. Solar cells always work with a load, thus under forward bias, but photodetectors sometimes work under reverse bias to maximize the photocurrent and minimize response time. Characterization of photodetectors usually includes the bandwidth, detectivity, linear dynamic range(LDR), and more. Besides, for photodiodes integrated in pixel arrays, e.g. intended for imaging or color detection, spectral response and bandwidth, cross-talk between pixels are also key factors to be considered.

\subsection{Characterization of OPDs}

The dark current of OPDs plays a key role for the overall performance of a photodetector. Not only does it strongly affect the noise level and efficiency of signal detection, but it is also the leakage current for read-out electronic circuits and defines the power consumption. The dark current is mainly determined by the electronic properties of the device, including the conductivity and the work function of the electrodes. Conductivity is related to carrier mobility, doping and trap density. Organic semiconductors are typically regarded as intrinsic since their bandgap usually is large $(>1.5 \mathrm{eV})$, and the density of thermally activated free charges is expected to be low. But in practical condition, due to the disorder and unavoidable surface doping, the carrier density is always much higher than expected, which decrease the shunt resistance. ${ }^{[107]}$ It has been reported that increasing the thickness or adding electron or hole blocking layers can effectively reduce the dark current. ${ }^{[108-110]}$ Dark current can be subtracted from the signal (dark plus photo current) but the fluctuations, i.e. noise, cannot be eliminated. Noise should be minimized to achieve high signal to noise ratio (SNR). 


\subsubsection{Noise and Detectivity}

Sources of noise in a diode includes: thermal noise, shot noise, $1 / f$ noise and generationrecombination noise, and more ${ }^{[111]}$ Thermal noise, also known as Johnson noise, is generated by thermally activated free charges inside electrical conductors at equilibrium. It is only determined by temperature and resistance. Shot noise originates from the discrete nature of electric charges, e.g., the random arrival or leaving on discrete time. It is proportional to the square root of total number of charges passing through. Both thermal and shot noise are independent of frequency. However, $1 / f$ noise and generation-recombination noise $\left(i_{g-r}\right)$ are frequency dependent, and both are complex and cannot be readily defined. The power spectral density of $1 / f$ noise is inversely proportional to frequency. In reference $46, i_{g-r}$ is defined as $i_{g-r}{ }^{2} \propto(\Delta N)^{2} \frac{4 \tau}{1+(2 \pi f \tau)^{2}}$, where $\tau$ is the lifetime of carriers and $\Delta \mathrm{N}$ is variation of carriers. The spectral density stays almost constant until $f=1 / 2 \pi f \tau$, and after that it decrease proportionally to $1 / f^{2}$. Equation 7.1 gives the expression for total noise, where $\mathrm{B}$ is the bandwidth of photodetector, $R_{s h}$ is the shunt resistance, $k_{B}$ is Boltzmann constant, $\mathrm{T}$ is temperature and $q$ is elementary charge.

$$
\begin{aligned}
i_{\text {total }}{ }^{2}= & i_{\text {thermal }}{ }^{2}+i_{\text {shot }}{ }^{2}+i_{1 / f}{ }^{2}+i_{G-R}{ }^{2} \\
& =\frac{4 k_{B} T}{R_{s h}} B+2 q I B+i_{1 / f}{ }^{2}(f, B)+i_{G-R}{ }^{2}(f, B)
\end{aligned}
$$

The total noise current is then the square root of integral over the bandwidth of a given photodiode. However, very often and in many published papers, the last two terms were ignored and sometimes, the thermal noise and the shot noise is taken for granted as the dominating source of noise. ${ }^{[112-114]}$ This could be true when dark current is high (cases under reverse bias). Only a few papers have considered the other sources of noise and measured rather than estimated the noise, in which the noise was in fact far beyond shot noise limit and showing domination of $1 / f^{n}$ noise with $n \geq 1$, which decreases dramatically with frequency increasing but sometimes can be still higher than shot noise even at $1 \mathrm{kHz}$. ${ }^{[108,115,116]}$

Measuring the noise is indeed quite difficult especially when it is small. At OV bias, both the shot noise and thermal noise can be extremely low, down to tens of $f A / \sqrt{ } \mathrm{Hz}$. Instruments with low internal noise as well as good enough shielding of both devices and connection cables are 
highly required for an accurate noise measurement. In paper 4, we tried to measure the noise under OV bias, but later we found the method used might be problematic. Alternative and more accurate methods and deeper understanding of noise measurement might be investigated in paper 3( under manuscript) but might not be fully included in this thesis.

Determination of noise level is important because it determines specific detectivity, one important figure of merit for a photodetector. Detectivity is defined as follows with where units is Jones, i.e. $\frac{\mathrm{cm} \cdot \sqrt{\mathrm{Hz}}}{W}$

$$
\begin{gathered}
D^{*}=\frac{\sqrt{A}}{N E P} \\
N E P=\frac{i_{\text {noise }}}{R \sqrt{\bar{B}}}
\end{gathered}
$$

where $A$ is the area of photodetector, NEP is noise equivalent power and $R$ is the responsivity. NEP is another figure of merit, defined as the optical power that can produce the same signal current as the noise current, i.e. SNR equal to 1 when the bandwidth is $1 \mathrm{~Hz}$. R is calculated from EQE of photodetector, as $R=\frac{\lambda}{h c} E Q E$ with unit $\mathrm{A} / \mathrm{W}$, where $\mathrm{h}$ is Planck constant, $\mathrm{c}$ is light speed, and $\lambda$ is wavelength. To calculate the detectivity, the noise must be quantified. Only considering shot noise rather than using the measured real noise then would overestimate the detectivity. However, as mentioned above, the use of measured noise is not adopted widely in this field, which as a result also makes the comparison of detectivity from different groups very difficult.

To increase the detectivity, two main strategies could be used: increase the EQE and suppress the noise. Increase the detector area could also increase detectivity, but also increases the total dark current and might increase noise in a faster rate. EQE of OPDs can easily reach as high as $70-80 \%$ nowadays, approaching $100 \%$ limit. Therefore, the noise current is dominating in determination of detectivity in those cases. Detectivity as high as $10^{12}$ Jones has been reported by many groups, among which some just considered the shot noise. ${ }^{[108,110,112,117]}$ Since the noise is usually very low, measuring the exact noise of a device is a huge challenge. It depends not only on devices itself but also the instruments used. That is why measuring noise is not widely adapted. But only considering the shot noise is obviously very inappropriate. In some cases, thermal noise could be higher than shot noise, especially under OV bias when current is 
extremely low. Table 7.1 give the estimated noise for TQ1:PNDI-T10 laminated all-polymer devices, both with Bilayer and $\mathrm{BHJ}$ configuration. The thermal noise is one order higher in both cases, dominating the total noise.

\begin{tabular}{l|l|l|l|l|l} 
& $\begin{array}{l}\text { Dark } \\
\text { current(A) } \\
\text { @oV }\end{array}$ & $\begin{array}{l}\text { Resistance } \\
(\mathbf{O h m})\end{array}$ & $\begin{array}{l}\text { Thermal } \\
\text { noise(A/Hz }\end{array}$ & $\begin{array}{l}\text { Shot } \\
\text { noise(A/Hz }\end{array}$ & $\begin{array}{l}\text { Sum } \\
\text { noise(A/Hz }\end{array}$ \\
\hline TQ1 Bilayer & $1.24 \mathrm{E}-11$ & $1.60 \mathrm{E}+08$ & $1.02 \mathrm{E}-14$ & $1.99 \mathrm{E}-15$ & $1.04 \mathrm{E}-14$ \\
\hline TQ1 BHJ & $2.28 \mathrm{E}-11$ & $3.08 \mathrm{E}+06$ & $7.34 \mathrm{E}-14$ & $2.70 \mathrm{E}-15$ & $7.34 \mathrm{E}-14$ \\
\hline
\end{tabular}

Table 7.1 shot and thermal noise estimated from I-V data. All devices have very low dark current at OV resulting in low shot current, one order lower than thermal noise in all cases.

\subsubsection{Dynamic Range}

Dynamic range represents the operational range of a photodetector. Within this range, it can capture the variation of the light intensity and gives out corresponding output. In practical applications, a linear dynamic range (LDR) is most preferred. LDR can be expressed as the ratio of the maximum $\left(I_{\max }\right)$ and minimum detectable current $\left(I_{\min }\right)$. At low light intensities, the bimolecular recombination is negligible, and the photocurrent increase linearly with light intensity. As light intensity increases, the photocurrent increases and after $I_{\max }$ it starts to deviate from linearity. The theoretical limit of $I_{\min }$ is the noise current, but for some cases, under extremely low light intensity, it could also deviate from linearity, therefore it is important to measure the LDR experimentally. LDR is usually expressed in $d B$ by Equation 7.4, where $P_{\max (\min )}$ is the maximum (minimum) light intensity. It should be noted that photocurrent proportional (by responsivity) to light intensity power, therefore these two definitions gives different LDR (doubled for 20 log definition). Careful attention should be taken when comparing LDR with different definition in different publications.

$$
L D R=20 \log \frac{I_{\max }}{I_{\min }} \text { or } 10 \log \frac{P_{\max }}{P_{\min }}
$$

In general, all strategies to reduce the bimolecular recombination is useful to increase the LDR, e.g. increase the mobility and decrease the thickness of active layer. For OPDs, $180 \mathrm{~dB}$ of LDR (9 order) has been reported by Armin et al., which to our knowledge is the highest. ${ }^{[118]}$ 


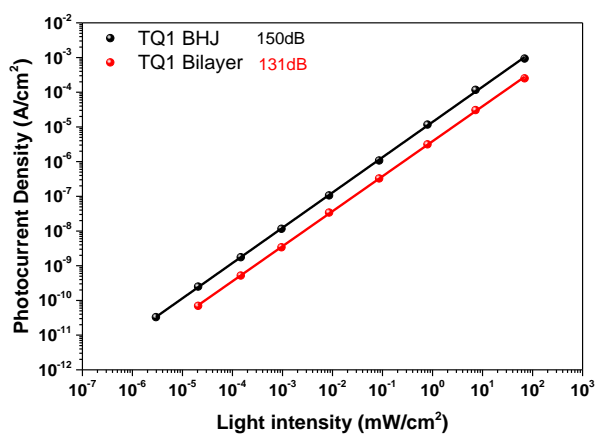

Figure 7.1 LDR for TQ1 BHJ and Bilayer devices. LDR was measured using lock-in amplifier under $450 \mathrm{~nm}$ blue light LED modulated at $200 \mathrm{~Hz}$. Bandwidth of lock-in amplifier was set to less than $0.1 \mathrm{~Hz}$. The noise floor then is limited by electromagnetic interference of instruments and cables rather than the device itself.

\subsubsection{Frequency Response}

Frequency response in OPDs represents how fast it can respond to light intensity variation. Bandwidth of a photodetector is defined as the modulation frequency of input light at which the response is half ( $3 \mathrm{~dB}$ lower than) of the continuous wave light response. The bandwidth is determined by both the carrier transit time and structure RC-time constant. Carrier transit time could be decreased simply by improving the carrier mobility and decrease thickness. However, decreasing the thickness meanwhile increase the structure capacitance and thus increase the RC time constant. Therefore, optimization should be done based on all these factors. Organic photodetectors with bandwidth between $\mathrm{kHz}$ to $\mathrm{MHz}$ have been widely reported, [105, 115, 119-122] but compared to inorganic ones with bandwidth up to hundreds of $\mathrm{GHz}$, the main limitation is the relatively low mobility. Figure 7.2 shows the frequency response of laminated TQ1 and PTB7-Th devices. Large area devices are 2 times larger than small area device, and it is observed that the structure RC does not limit. The Bilayer ones have higher bandwidth than $\mathrm{BHJ}$ ones, which could be attributed to the improved mobility and decreased active thickness. 

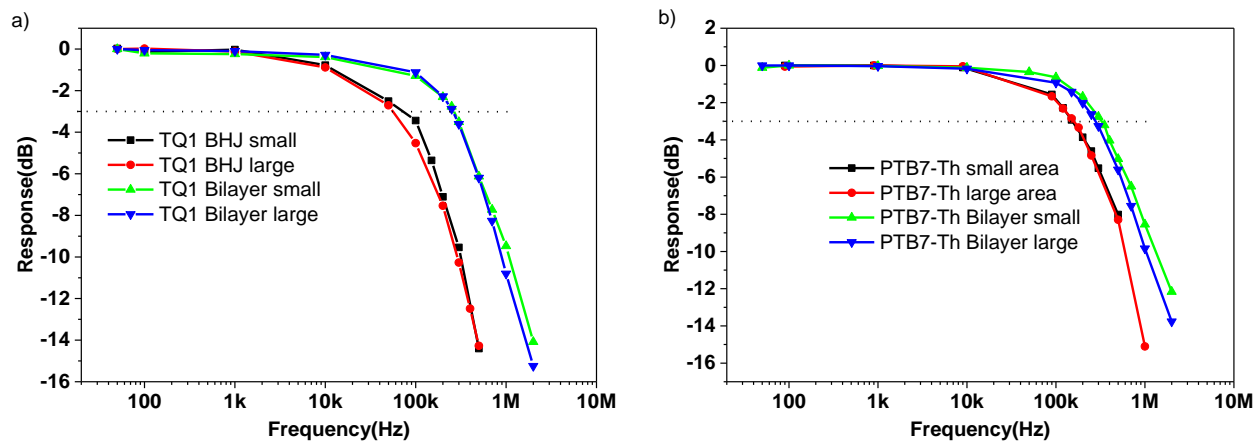

Figure 7.2 Frequency response of a)TQ1 BHJ and Bilayer devices b) PTB7-Th BHJ and Bilayer.

\subsection{All polymer OPDs through lamination}

Efficient OPDs are usually composed of blend of donor and acceptor as active material, either in bulk heterojunction (BHJ) or bilayer configuration. Compared to polymer/fullerene OPDs have advantages on mechanical robustness and more flexibility of response range design. Combined

with roll-to-roll compatible lamination method ${ }^{[89,123]}$, $\mathrm{BHJ}$ or bilayer could be easily fabricated. Compared with $\mathrm{BHJ}$ devices, Bilayer devices might have lower photocurrent but also suppress the dark current and decrease carrier transit time.

In Paper 3, we introduced two all polymer blend:TQ1/PNDI-T10 and PTb7-Th/PNDI-T10 both in $\mathrm{BHJ}$ and bilayer configuration through lamination for photodetection. Many characterizations based on what we discuss above were done and comparison between these two blends and between BHJ and Bilayer configuration were addressed. Laminated PTB7-Th BHJ device shows high detectivity up to $10^{12}$ Jones under OV bias. The TQ1 bilayer devices shows even higher detectivity than the $\mathrm{BHJ}$ devices, and detectivity reaching $10^{11}$. Lamination offers us an easy way to make bilayer devices which could be superior to BHJ devices in terms of detectivity and bandwidth. 


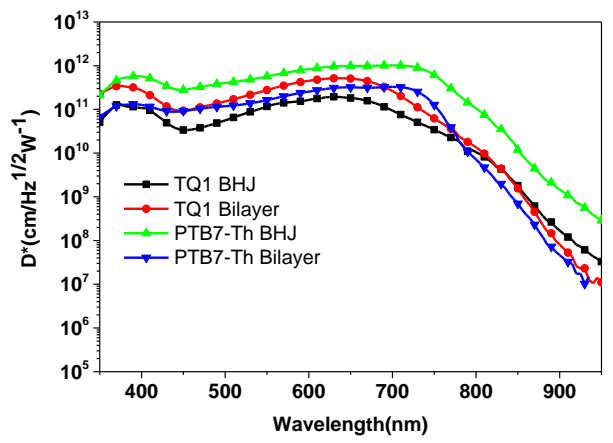

Figure 7.3 Detectivity of TQ1 and PTB7-Th laminated devices.

\section{Outlook}

OPV has achieved remarkable progress in the last three years, from 11\% in 2016 to the highest PCE $17.3 \%$ that reported during the writing of this thesis, and $>25 \%$ would be achievable as predicted by the author. Tandem devices and both ternary and binary blend are applied as active layers. I believe researchers will follow this route and promote the PCE to $>20 \%$ in the next few years. Therefore, the large production of OPVs would become more and more practical and attractive to the market. More novel application of OPV fully utilizing its flexibility and semitransparency will come to compete with inorganic solar cells. More and more study on printing and roll-to-roll compatible methods of flexible large area OPVs should be put on agenda and so does the in-air production stability and mechanical robustness study. Morphology study based on printed rather than spin-coated films should draw more attentions. In addition, high selectivity of contact layers and conductivity of electrodes are also key points for printable OPV. As the most practical electrode candidates, PEDOT(PSS) along with appropriate contact layers has shown great potentials. With CELIV method for selectivity characterization, more efficient combination would be identified in future.

Though polymer/polymer blends now are lagging behind polymer/non-fullerene small molecule blends, with $9 \%$ vs $14 \%$ of PCE, considering the potential advantages of mechanical robustness, it is still worthy more efforts for searching for new polymer acceptors with low cost and improved stability. 
Along with huge progress of OPV, OPD have also been leaping forward. Thanks to new organic materials with high mobility and extended absorption range, OPDs with large bandwidth, wide spectral detection range and high detectivity have emerged. Taking advantage of flexibility and low cost, many novel applications are becoming practical in the near future.

Apparently, the remarkable progress in OPV and OPD would keep this field hot in the next a few years and attract more researchers devoting into not only searching for new materials but also finding out physics behind.

\section{Acknowledgements}

This thesis composes work done in the group of Biomolecular and Organic Electronics (Biorgel) at Department of Physics, Chemistry and Biology, Linköping University. I would like to express my deepest thanks to Professor Olle Inganäs, who is the leader of Biorgel and a great scientist as well as my supervisor. I am so grateful that Olle has taken me as his PhD student and I have learnt so much from him about how to do science innovatively and critically. His positive attitude both to science and life has shamed but also encouraged me a lot. I am also very grateful for his encouragement and great patience while I was in poor health situations during my PhD study.

I would like to thank Ergang Wang from Chalmers University of Technology, who introduced me to this group five years ago and who is also my co-supervisor. Without him, I have no chance to work in this great group. Great thanks for his great instructions at the beginning of my study here and his arrangements of collaboration with other groups. Thank Prof. Fengling Zhang as my mentor for her help in lab work and life.

I would like to thank all the Biorgel members who have helped me, and I have helped in the last 5 years. Thank Dr. Zheng Tang for his guide when I was a newcomer and his teaching about the lab instruments. Thank Dr. Feng Gao for his teaching me how to do FTPS and EL/PL measurements and arranging many collaborations ending up with excellent publications. He also gave me a lot of great advices and inspirations. Great thanks to Mr. Thomas Österberg who helped me so much about the fabrication of laminated devices and teach me lots of wonderful 
tricks and some Swedish words and history. It was never boring to work with him. Thank Dr. Jonas Bergqvist for helping with ellipsometry measurements and some wonderful discussion. Thank Dr. Luis Ever Aguirre for great support as lab engineer, without which my experiments would not have gone on well. Thank Dr. Chiara Musumeci who helped with conductive-AFM. Thank Xiaofeng Xu for supplying of organic materials.

Thanks for collaborators from China: Dr. Jianyu Yuan, Shenkun Xie, Prof. Yuan Zhang, Prof. Wanli Ma.

I also would like to express my gratitude to the following people: Niclas Solin, Armantas Melianas, Wanzhu Cai, Yingzhi Jin, Chuanfei Wang, Qingzhen Bian, Yuttapoom Puttisong, Zhibo Yan, Chunxiong Bao, Yuqing Huang, Jian Qing, Fátima Ajjan, Yuming Wang, Huotian Zhang, Zhongcheng Yuan, Sai Bai, Mingtao Lv, Deping Qian, Bo Liu, Zaifei Ma.

I would like to thank China Scholarship Council(CSC) for financial support of four years of PhD study.

Finally, great thanks to my family and friends in China. 


\section{References}

[1] J. Nelson, The Physics of Solar Cells, Imperial College Press, 2013.

[2] G. M. A., H. Yoshihiro, D. E. D., L. D. H., H.-E. Jochen, H.-B. A. W.Y., Progress in Photovoltaics: Research and Applications 2018, 26, 3.

[3] F. Suzuki, S. Kubo, T. Fukushima, H. Kaji, Scientific Reports 2018, 8, 5203.

[4] M. Schwoerer, H. C. Wolf, Organic Molecular Solids, Wiley-VCH, 2008.

[5] J. C. Blakesley, D. Neher, Phys Rev B 2011, 84.

[6] A. Miller, E. Abrahams, Phys. Rev. 1960, 120, 745.

[7] G. D. Scholes, Annu. Rev. Phys. Chem. 2003, 54, 57.

[8] D. L. Dexter, The Journal of Chemical Physics 1953, 21, 836.

[9] E. M. Y. Lee, W. A. Tisdale, A. P. Willard, The Journal of Physical Chemistry B 2015, $119,9501$.

[10] G. Yu, J. Gao, J. C. Hummelen, F. Wudl, A. J. Heeger, Science 1995, 270, 1789.

[11] J. Liu, S. Chen, D. Qian, B. Gautam, G. Yang, J. Zhao, J. Bergqvist, F. Zhang, W. Ma, H. Ade, O. Inganäs, K. Gundogdu, F. Gao, H. Yan, Nat. Energy 2016, 1, 16089.

[12] B. Bernardo, D. Cheyns, B. Verreet, R. D. Schaller, B. P. Rand, N. C. Giebink, Nat. Commun. 2014, 5, 3245.

[13] D. E. Markov, C. Tanase, P. W. M. Blom, J. Wildeman, Phys Rev B 2005, 72, 045217.

[14] L. R. R., B. J. B., F. S. R., Adv Mater 2010, 22, 1233.

[15] S. M. Hubig, J. K. Kochi, J. Phys. Chem. 1995, 99, 17578.

[16] N. S. Sariciftci, L. Smilowitz, A. J. Heeger, F. Wudl, Science 1992, 258, 1474.

[17] C. J. Brabec, G. Zerza, G. Cerullo, S. De Silvestri, S. Luzzati, J. C. Hummelen, S. Sariciftci, Chem. Phys. Lett. 2001, 340, 232.

[18] I.-W. Hwang, D. Moses, A. J. Heeger, The Journal of Physical Chemistry C 2008, 112, 4350 .

[19] H. I.-W., S. C., M. D., Z. Z., W. D., G. R., B. C. J., H. A. J., Adv Mater 2007, 19, 2307.

[20] F. Gao, O. Inganäs, PCCP 2014, 16, 20291.

[21] F. Gao, W. Tress, J. Wang, O. Inganäs, Phys. Rev. Lett. 2015, 114, 1.

[22] A. Melianas, F. Etzold, T. J. Savenije, F. Laquai, O. Inganäs, M. Kemerink, Nat. Commun. 2015, 6 . 
[23] A. Melianas, V. Pranculis, A. Devizis, V. Gulbinas, O. Inganäs, M. Kemerink, Adv. Funct. Mater. 2014, 24, 4507.

[24] A. Melianas, V. Pranculis, Y. X. Xia, N. Felekidis, O. Inganäs, V. Gulbinas, M. Kemerink, Adv Energy Mater 2017, 7.

[25] K. Vandewal, S. Albrecht, E. T. Hoke, K. R. Graham, J. Widmer, J. D. Douglas, M. Schubert, W. R. Mateker, J. T. Bloking, G. F. Burkhard, A. Sellinger, J. M. J. Frechet, A. Amassian, M. K. Riede, M. D. McGehee, D. Neher, A. Salleo, Nat Mater 2014, 13, 63.

[26] J. Kurpiers, T. Ferron, S. Roland, M. Jakoby, T. Thiede, F. Jaiser, S. Albrecht, S. Janietz, B. A. Collins, I. A. Howard, D. Neher, Nat. Commun. 2018, 9, 2038.

[27] J. A. Bartelt, Z. M. Beiley, E. T. Hoke, W. R. Mateker, J. D. Douglas, B. A. Collins, J. R. Tumbleston, K. R. Graham, A. Amassian, H. Ade, J. M. J. Frechet, M. F. Toney, M. D. McGehee, Adv Energy Mater 2013, 3, 364.

[28] Y. Y. Liang, Z. Xu, J. B. Xia, S. T. Tsai, Y. Wu, G. Li, C. Ray, L. P. Yu, Adv Mater 2010, 22, E135.

[29] J. H. Hou, H. Y. Chen, S. Q. Zhang, R. I. Chen, Y. Yang, Y. Wu, G. Li, J. Am. Chem. Soc. 2009, 131, 15586.

[30] S. Gélinas, A. Rao, A. Kumar, S. L. Smith, A. W. Chin, J. Clark, T. S. van der Poll, G. C. Bazan, R. H. Friend, Science 2014, 343, 512.

[31] S. M. Falke, C. A. Rozzi, D. Brida, M. Maiuri, M. Amato, E. Sommer, A. De Sio, A. Rubio, G. Cerullo, E. Molinari, C. Lienau, Science 2014, 344, 1001.

[32] B. M. Savoie, A. Rao, A. A. Bakulin, S. Gelinas, B. Movaghar, R. H. Friend, T. J. Marks, M. A. Ratner, J. Am. Chem. Soc. 2014, 136, 2876.

[33] M. Casalegno, R. Pastore, J. Idé, R. Po, G. Raos, The Journal of Physical Chemistry C 2017, 121, 16693.

[34] J. Benduhn, K. Tvingstedt, F. Piersimoni, S. Ullbrich, Y. L. Fan, M. Tropiano, K. A. McGarry, O. Zeika, M. K. Riede, C. J. Douglas, S. Barlow, S. R. Marder, D. Neher, D. Spoltore, K. Vandewal, Nat. Energy 2017, 2.

[35] L. J. A. Koster, E. C. P. Smits, V. D. Mihailetchi, P. W. M. Blom, Phys Rev B 2005, 72, 085205 .

[36] T. Kirchartz, J. Nelson, Phys. Rev. B 2012, 86.

[37] M. Hilczer, M. Tachiya, The Journal of Physical Chemistry C 2010, 114, 6808. 
[38] A. Spies, M. List, T. Sarkar, U. Würfel, Adv Energy Mater 2017, 7, 1601750.

[39] G. Garcia-Belmonte, Sol. Energy Mater. Sol. Cells 2010, 94, 2166.

[40] J. C. Blakesley, D. Neher, Phys Rev B 2011, 84, 075210.

[41] U. Rau, Phys Rev B 2007, 76, 085303.

[42] U. Rau, B. Blank, T. C. M. Müller, T. Kirchartz, Physical Review Applied 2017, 7, 044016.

[43] T. M. Burke, S. Sweetnam, K. Vandewal, M. D. McGehee, Adv Energy Mater 2015, 5.

[44] K. Vandewal, K. Tvingstedt, A. Gadisa, O. Inganäs, J. V. Manca, Nat Mater 2009, 8, 904.

[45] K. Vandewal, K. Tvingstedt, A. Gadisa, O. Inganäs, J. V. Manca, Phys Rev B 2010, 81, 125204.

[46] M. O. Osotov, V. V. Bruevich, D. Y. Paraschuk, The Journal of Chemical Physics 2009, $131,094906$.

[47] G. Wantz, L. Hirsch, N. Huby, L. Vignau, A. S. Barrière, J. P. Parneix, J. Appl. Phys. 2005, 97, 034505.

[48] K. Vandewal, L. Goris, I. Haeldermans, M. Nesládek, K. Haenen, P. Wagner, J. V. Manca, Thin Solid Films 2008, 516, 7135.

[49] F. Gao, S. Himmelberger, M. Andersson, D. Hanifi, Y. X. Xia, S. Q. Zhang, J. P. Wang, J. H. Hou, A. Salleo, O. Inganäs, Adv Mater 2015, 27, 3868.

[50] A. A. Bakulin, Y. Xia, H. J. Bakker, O. Inganäs, F. Gao, The Journal of Physical Chemistry C 2016, 120, 4219.

[51] R. A. Marcus, The Journal of Physical Chemistry 1989, 93, 3078.

[52] I. R. Gould, D. Noukakis, L. Gomez-Jahn, R. H. Young, J. L. Goodman, S. Farid, Chem. Phys. 1993, 176, 439.

[53] L. J. A. Koster, V. D. Mihailetchi, H. Xie, P. W. M. Blom, Appl. Phys. Lett. 2005, 87, 203502.

[54] V. D. Mihailetchi, J. Wildeman, P. W. M. Blom, Phys. Rev. Lett. 2005, 94, 126602.

[55] T. Kirchartz, F. Deledalle, P. S. Tuladhar, J. R. Durrant, J. Nelson, J Phys Chem Lett 2013, 4, 2371.

[56] V. V. Brus, Org. Electron. 2016, 29, 1.

[57] A. Petersen, T. Kirchartz, T. A. Wagner, Phys Rev B 2012, 85. 
[58] O. J. Sandberg, S. Sanden, A. Sundqvist, J. H. Smatt, R. Osterbacka, Phys. Rev. Lett. 2017, 118 .

[59] S. Sanden, O. Sandberg, Q. Xu, J.-H. Smatt, G. Juska, M. Linden, R. Osterbacka, PCCP 2012, 14, 14186.

[60] U. Würfel, A. Cuevas, P. Würfel, IEEE Journal of Photovoltaics 2015, 5, 461.

[61] S. S. Li, L. Ye, W. C. Zhao, S. Q. Zhang, S. Mukherjee, H. Ade, J. H. Hou, Adv. Mater. 2016, 28, 9423.

[62] W. Zhao, S. Li, H. Yao, S. Zhang, Y. Zhang, B. Yang, J. Hou, J. Am. Chem. Soc. 2017, $139,7148$.

[63] S. Li, L. Ye, W. Zhao, H. Yan, B. Yang, D. Liu, W. Li, H. Ade, J. Hou, J. Am. Chem. Soc. 2018.

[64] L. Meng, Y. Zhang, X. Wan, C. Li, X. Zhang, Y. Wang, X. Ke, Z. Xiao, L. Ding, R. Xia, H.-L. Yip, Y. Cao, Y. Chen, Science 2018.

[65] Z. Li, X. Xu, W. Zhang, X. Meng, W. Ma, A. Yartsev, O. Inganäs, M. R. Andersson, R. A. J. Janssen, E. Wang, J. Am. Chem. Soc. 2016, 138, 10935.

[66] H. Yan, Z. Chen, Y. Zheng, C. Newman, J. R. Quinn, F. Dötz, M. Kastler, A. Facchetti, Nature 2009, 457, 679.

[67] L. Gao, Z.-G. Zhang, L. Xue, J. Min, J. Zhang, Z. Wei, Y. Li, Adv Mater 2016, 28, 1884.

[68] H. Kang, M. A. Uddin, C. Lee, K.-H. Kim, T. L. Nguyen, W. Lee, Y. Li, C. Wang, H. Y. Woo, B. J. Kim, J. Am. Chem. Soc. 2015, 137, 2359.

[69] S. Dai, F. Zhao, Q. Zhang, T.-K. Lau, T. Li, K. Liu, Q. Ling, C. Wang, X. Lu, W. You, X. Zhan, J. Am. Chem. Soc. 2017, 139, 1336.

[70] J. Zhao, Y. Li, G. Yang, K. Jiang, H. Lin, H. Ade, W. Ma, H. Yan, Nature Energy 2016, $1,15027$.

[71] A. Facchetti, Mater. Today 2013, 16, 123.

[72] N. Balar, Y. Xiong, L. Ye, S. Li, D. Nevola, D. B. Dougherty, J. Hou, H. Ade, B. T. O'Connor, ACS Applied Materials and Interfaces 2017, 9, 43886.

[73] W. Kim, J. Choi, J.-H. Kim, T. Kim, C. Lee, S. Lee, M. Kim, B. J. Kim, T.-S. Kim, Chem. Mater. 2018, 30, 2102.

[74] D. Mori, H. Benten, I. Okada, H. Ohkita, S. Ito, Advanced Energy Materials 2014, 4, n/a. 
[75] N. Zhou, H. Lin, S. J. Lou, X. Yu, P. Guo, E. F. Manley, S. Loser, P. Hartnett, H. Huang, M. R. Wasielewski, L. X. Chen, R. P. H. Chang, A. Facchetti, T. J. Marks, Adv Energy Mater 2014, 4, n/a.

[76] J. W. Jung, J. W. Jo, C.-C. Chueh, F. Liu, W. H. Jo, T. P. Russell, A. K. Y. Jen, Advanced Materials 2015, n/a.

[77] Y. Zhou, T. Kurosawa, W. Ma, Y. K. Guo, L. Fang, K. Vandewal, Y. Diao, C. G. Wang, Q. F. Yan, J. Reinspach, J. G. Mei, A. L. Appleton, G. I. Koleilat, Y. L. Gao, S. C. B. Mannsfeld, A. Salleo, H. Ade, D. H. Zhao, Z. N. Bao, Adv Mater 2014, 26, 3767.

[78] D. Mori, H. Benten, I. Okada, H. Ohkita, S. Ito, Energy \& Environmental Science 2014.

[79] H. Yan, Z. Chen, Y. Zheng, C. Newman, J. R. Quinn, F. Dotz, M. Kastler, A. Facchetti, Nature 2009, 457, 679.

[80] Z. Li, X. Xu, W. Zhang, X. Meng, Z. Genene, W. Ma, W. Mammo, A. Yartsev, M. R. Andersson, R. A. J. Janssen, E. Wang, Energy \& Environmental Science 2017, 10, 2212.

[81] Y. Lin, S. Dong, Z. Li, W. Zheng, J. Yang, A. Liu, W. Cai, F. Liu, Y. Jiang, T. P. Russell, F. Huang, E. Wang, L. Hou, Nano Energy 2018, 46, 428.

[82] L. Ye, Y. Xiong, S. Li, M. Ghasemi, N. Balar, J. Turner, A. Gadisa, J. Hou, B. T. O'Connor, H. Ade, Adv. Funct. Mater. 2017, 27, 1702016.

[83] Y.-H. Chang, S.-R. Tseng, C.-Y. Chen, H.-F. Meng, E.-C. Chen, S.-F. Horng, C.-S. Hsu, Org. Electron. 2009, 10, 741.

[84] J.-W. Kang, Y.-J. Kang, S. Jung, M. Song, D.-G. Kim, C. Su Kim, S. H. Kim, Sol Energ Mat Sol C 2012, 103, 76.

[85] L. Ye, Y. Xiong, Q. Zhang, S. Li, C. Wang, Z. Jiang, J. Hou, W. You, H. Ade, Adv Mater 2018, 30, 1705485.

[86] T. T. Larsen-Olsen, R. R. Sondergaard, K. Norrman, M. Jorgensen, F. C. Krebs, Energy \& Environmental Science 2012, 5, 9467.

[87] Z. Tang, Z. George, Z. Ma, J. Bergqvist, K. Tvingstedt, K. Vandewal, E. Wang, L. M. Andersson, M. R. Andersson, F. Zhang, O. Inganäs, Adv Energy Mater 2012, 2, 1467.

[88] F. Zhang, M. Johansson, M. R. Andersson, J. C. Hummelen, O. Inganäs, Adv. Mater. 2002, 14, 662 .

[89] J. Bergqvist, T. Österberg, A. Melianas, L. Ever Aguirre, Z. Tang, W. Cai, Z. Ma, M. Kemerink, D. Gedefaw, M. R. Andersson, O. Inganäs, npj Flexible Electronics 2018, 2, 4. 
[90] H. Melchior, M. B. Fisher, F. R. Arams, Proc. IEEE 1970, 58, 1466.

[91] E. H. Sargent, Adv. Mater. 2005, 17, 515.

[92] R. D. Jansen-van Vuuren, A. Armin, A. K. Pandey, P. L. Burn, P. Meredith, Adv. Mater. 2016, 28, 4766.

[93] S. Kim, Y. T. Lim, E. G. Soltesz, A. M. De Grand, J. Lee, A. Nakayama, J. A. Parker, T. Mihaljevic, R. G. Laurence, D. M. Dor, L. H. Cohn, M. G. Bawendi, J. V. Frangioni, Nat. Biotechnol. 2003, 22, 93.

[94] E. Manna, T. Xiao, J. Shinar, R. Shinar, Electronics 2015, 4, 688.

[95] K. S. Nalwa, Y. Cai, A. L. Thoeming, J. Shinar, R. Shinar, S. Chaudhary, Adv. Mater. 2010, 22, 4157.

[96] P. Büchele, M. Richter, S. F. Tedde, G. J. Matt, G. N. Ankah, R. Fischer, M. Biele, W. Metzger, S. Lilliu, O. Bikondoa, J. E. Macdonald, C. J. Brabec, T. Kraus, U. Lemmer, O. Schmidt, Nature Photonics 2015, 9, 843.

[97] H. M. Thirimanne, K. D. G. I. Jayawardena, A. J. Parnell, R. M. I. Bandara, A. Karalasingam, S. Pani, J. E. Huerdler, D. G. Lidzey, S. F. Tedde, A. Nisbet, C. A. Mills, S. R. P. Silva, Nat. Commun. 2018, 9, 2926.

[98] J. J. M. Halls, C. A. Walsh, N. C. Greenham, E. A. Marseglia, R. H. Friend, S. C. Moratti, A. B. Holmes, Nature 1995, 376, 498.

[99] N. S. Sariciftci, D. Braun, C. Zhang, V. I. Srdanov, A. J. Heeger, G. Stucky, F. Wudl, Appl. Phys. Lett. 1993, 62, 585.

[100] L. S. Roman, M. R. Andersson, T. Yohannes, O. Inganás, Adv. Mater. 1997, 9, 1164.

[101] G. Azzellino, A. Grimoldi, M. Binda, M. Caironi, D. Natali, M. Sampietro, Adv. Mater. 2013, 25, 6829 .

[102] X. Gong, M. Tong, Y. Xia, W. Cai, J. S. Moon, Y. Cao, G. Yu, C.-L. Shieh, B. Nilsson, A. J. Heeger, Science 2009, 325, 1665.

[103] J. D. Zimmerman, V. V. Diev, K. Hanson, R. R. Lunt, E. K. Yu, M. E. Thompson, S. R. Forrest, Adv. Mater. 2010, 22, 2780.

[104] J. B. Wang, W. L. Li, B. Chu, C. S. Lee, Z. S. Su, G. Zhang, S. H. Wu, F. Yan, Org. Electron. 2011, 12, 34.

[105] M. Ramuz, L. Bürgi, C. Winnewisser, P. Seitz, Org. Electron. 2008, 9, 369. 
[106] T. N. Ng, W. S. Wong, M. L. Chabinyc, S. Sambandan, R. A. Street, Appl. Phys. Lett. 2008, 92, 213303.

[107] A. J. Morfa, A. M. Nardes, S. E. Shaheen, N. Kopidakis, J. van de Lagemaat, Adv. Funct. Mater. 2011, 21, 2580.

[108] A. Armin, R. D. Jansen-van Vuuren, N. Kopidakis, P. L. Burn, P. Meredith, Nat. Commun. 2015, 6, 6343.

[109] D. M. Lyons, A. Armin, M. Stolterfoht, R. C. R. Nagiri, R. D. Jansen-van Vuuren, B. N. Pal, P. L. Burn, S.-C. Lo, P. Meredith, Org. Electron. 2014, 15, 2903.

[110] X. Xu, X. Zhou, K. Zhou, Y. Xia, W. Ma, O. Inganäs, Adv. Funct. Mater. 2018, 1805570.

[111] Bogdan M. Wilamowski, J. D. Irwin, Fundamentals of Industrial Electronics, CRC Press, 2011.

[112] C. M. Benavides, P. Murto, C. L. Chochos, V. G. Gregoriou, A. Avgeropoulos, X. Xu, K. Bini, A. Sharma, M. R. Andersson, O. Schmidt, C. J. Brabec, E. Wang, S. F. Tedde, ACS Applied Materials \& Interfaces 2018, 10, 12937.

[113] H. Zhang, S. Jenatsch, J. De Jonghe, F. Nüesch, R. Steim, A. C. Véron, R. Hany, Sci Rep-Uk 2015, 5, 9439.

[114] Z. Liu, K. Parvez, R. Li, R. Dong, X. Feng, K. Müllen, Adv. Mater. 2015, 27, 669.

[115] Y. Yao, Y. Liang, V. Shrotriya, S. Xiao, L. Yu, Y. Yang, Adv. Mater. 2007, 19, 3979.

[116] L. Dou, Y. Yang, J. You, Z. Hong, W.-H. Chang, G. Li, Y. Yang, Nat. Commun. 2014, 5, 5404.

[117] E. Saracco, B. Bouthinon, J.-M. Verilhac, C. Celle, N. Chevalier, D. Mariolle, O. Dhez, J.-P. Simonato, Adv. Mater. 2013, 25, 6534.

[118] A. Armin, M. Hambsch, I. K. Kim, P. L. Burn, P. Meredith, E. B. Namdas, Laser \& Photonics Reviews 2014, 8, 924.

[119] T. Morimune, H. Kajii, Y. Ohmori, IEEE Photonics Technology Letters 2006, 18, 2662.

[120] D. Yang, X. Zhou, D. Ma, Org. Electron. 2013, 14, 3019.

[121] T. Hamasaki, T. Morimune, H. Kajii, S. Minakata, R. Tsuruoka, T. Nagamachi, Y. Ohmori, Thin Solid Films 2009, 518, 548.

[122] D. Baierl, B. Fabel, P. Gabos, L. Pancheri, P. Lugli, G. Scarpa, Org. Electron. 2010, 11, 1199. 
[123] Y. Xia, X. Xu, L. E. Aguirre, O. Inganäs, Journal of Materials Chemistry A 2018, 6, 21186. 
Appendix I: Chemical Structure of Involved Materials
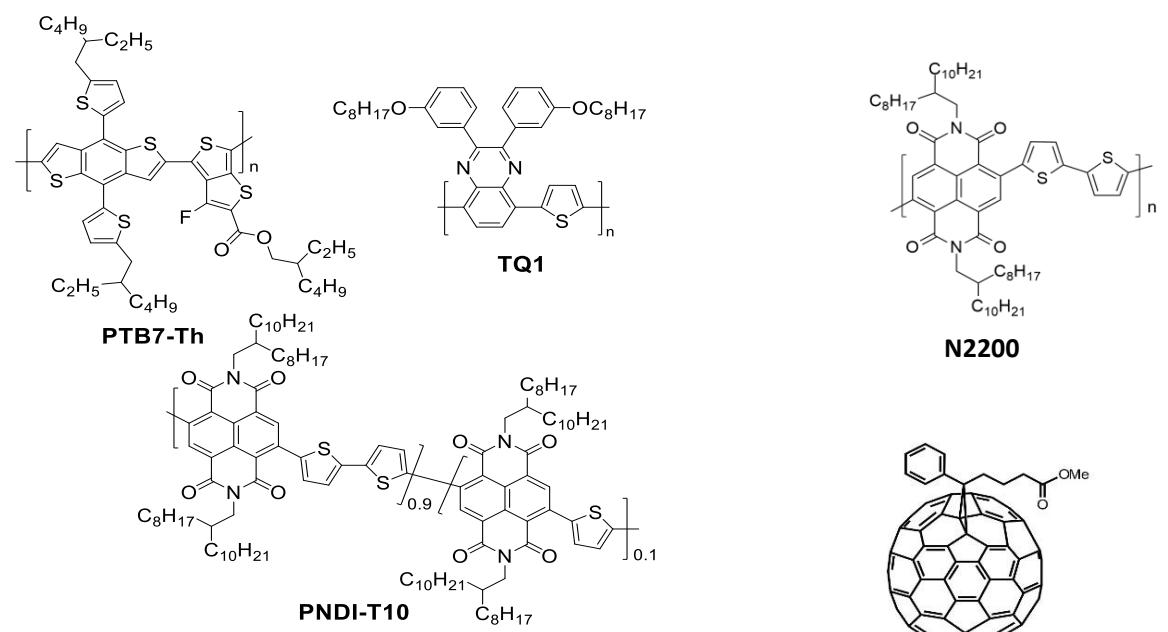

N2200

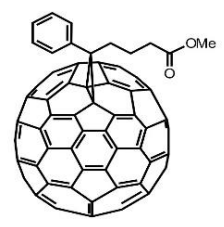

PCBM[70]
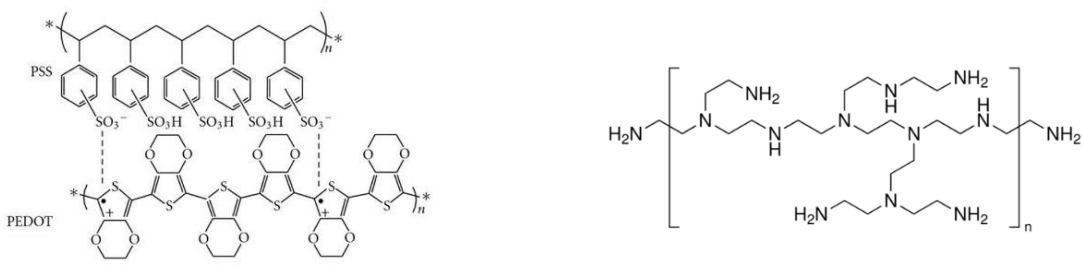

PEDOT:PSS

PEI

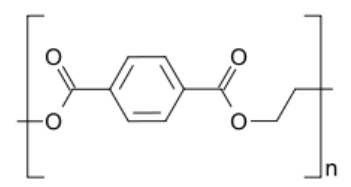

PET 


\section{Appendix II: Abbreviations and Symbols}

\begin{tabular}{|c|c|}
\hline short circuit current & $J_{s c}$ \\
\hline internal quantum efficiency & IQE \\
\hline external quantum efficiency & EQE \\
\hline dark current & $J_{\text {dark }}$ \\
\hline saturation current & $J_{0}$ \\
\hline temperature & $T$ \\
\hline open circuit voltage & $V_{\text {oc }}$ \\
\hline fill factor & $\mathrm{FF}$ \\
\hline power conversion efficiency & PCE \\
\hline Series resistance & $R_{S}$ \\
\hline shunt resistance & $\mathrm{R}_{s h}$ \\
\hline angular factor of sun & $F_{s}$ \\
\hline angular factor of ambient & $F_{a}$ \\
\hline chemical potential & $\Delta \mu$ \\
\hline power conversion efficiency & $\eta$ \\
\hline bandgap & $E_{\mathrm{g}}$ \\
\hline highest unoccupied molecular orbital & HOMO \\
\hline lowest occupied molecular orbital & LUMO \\
\hline Fröster resonance energy transfer & FRET \\
\hline Gaussian disorder model & GDM \\
\hline bulk heterojunction & $\mathrm{BHJ}$ \\
\hline charge transfer state & CTS \\
\hline binding energy & $E_{\mathrm{B}}$ \\
\hline Boltzmann constant & $k_{\mathrm{B}}$ \\
\hline Planck constant & $\mathrm{h}$ \\
\hline light speed & c \\
\hline
\end{tabular}




\begin{tabular}{|c|c|}
\hline diffusion length & $L_{D}$ \\
\hline Shockley-Read-Hall recombination rate & $R_{S R H}$ \\
\hline Langevin recombination rate & $\gamma$ \\
\hline lifetime of captured electron or hole by traps & $\tau_{n, p, S R H}$ \\
\hline density of states & DOS \\
\hline surface recombination velocity & $S_{R}$ \\
\hline electron density & $\mathrm{n}$ \\
\hline hole density & $\mathrm{p}$ \\
\hline quasi-Fermi level of electron & $E_{\mathrm{fn}}$ \\
\hline quasi-Fermi level of hole & $E_{\mathrm{fp}}$ \\
\hline standard deviation & $\sigma$ \\
\hline electroluminescence efficiency & $E Q E_{E L}$ \\
\hline radiative limit of $V_{o c}$ & $V_{o c}^{r a d}$ \\
\hline reorganization energy & $\lambda$ \\
\hline wavenumber & $\kappa$ \\
\hline charge transfer state energy & $E_{\mathrm{ct}}$ \\
\hline donor & $\mathrm{D}$ \\
\hline acceptor & A \\
\hline electroluminescence & $\mathrm{EL}$ \\
\hline photoluminescence & $\mathrm{PL}$ \\
\hline charge extraction by linearly increasing voltage & CELIV \\
\hline polyethyleneimine & PEI \\
\hline zinc oxide & $\mathrm{ZnO}$ \\
\hline organic photodetector & OPD \\
\hline noise equivalent power & NEP \\
\hline linear dynamic range & LDR \\
\hline detectivity & $D^{*}$ \\
\hline
\end{tabular}





\section{Publications}

The publications associated with this thesis have been removed for copyright reasons. For more details about these see:

http://urn.kb.se/resolve?urn=urn:nbn:se:liu:diva-153616 



\section{FACULTY OF SCIENCE AND ENGINEERING}

Linköping Studies in Science and Technology, Dissertations, No. 1974, 2018 Department of Physics, Chemistry and Biology (IFM)

Biomolecular and Organic Electronics

Linköping University

SE-581 83 Linköping, Sweden

www.liu.se 